\title{
Re-recognizing Micro Locations of Nanoscale Zero- valent Iron in Biochar Using C-TEM technique
}

\section{Kun Yang ( $\nabla$ kyang@zju.edu.cn )}

Zhejiang University

Jialu Xu

Zhejiang University

Ming Zhang

China Jiliang University

Daohui Lin

Zhejiang University

\section{Research Article}

Keywords: Nanoscale zero-valent iron, Biochar, Cross-sectional TEM, Interior morphology, Biochar supported nanoscale zero-valent iron, SEM

Posted Date: December 28th, 2020

DOl: https://doi.org/10.21203/rs.3.rs-133740/v1

License: (c) (1) This work is licensed under a Creative Commons Attribution 4.0 International License. Read Full License

Version of Record: A version of this preprint was published at Scientific Reports on March 3rd, 2021. See the published version at https://doi.org/10.1038/s41598-021-84685-w. 


\section{Re-recognizing Micro Locations of Nanoscale Zero-valent Iron in Biochar}

\section{Using C-TEM technique}

$4 \quad{ }^{1}$ Department of Environmental Science, Zhejiang University, Hangzhou 310058, China

$5{ }^{2}$ Key Laboratory of Environmental Pollution and Ecological Health of Ministry of Education, Hangzhou 310058,

6 China

$7 \quad{ }^{3}$ Zhejiang Provincial Key Laboratory of Organic Pollution Process and Control, Hangzhou 310058, China

$8 \quad{ }^{4}$ Department of Environmental Engineering, China Jiliang University, Hangzhou, 310028, China

$9 \quad{ }^{*}$ Corresponding author (Kun Yang). Tel: 86-571-88982589; Fax: 86-571-88982590; E-mail: kyang@ @ju.edu.cn 10 
11 Abstract: Biochar supported nanoscale zero-valent iron (NZVI/BC), prepared commonly by liquid reduction using sodium borohydride $\left(\mathrm{NaBH}_{4}\right)$, exhibits better reduction performance for contaminants than bulk NZVI. The better reducing ability was attributed to attachment of nanoscale zero-valent iron (NZVI) on biochar (BC) surface or into the interior pores of $\mathrm{BC}$ particles due to observations by scanning electron microscopy (SEM) and plan transmission electron microscopy (P-TEM) techniques in previous studies. In this study, cross-sectional TEM (C-TEM) technique was employed firstly to explore location of NZVI in NZVI/BC. It was observed that NZVI is isolated from BC particles, but not located on the surface or in the interior pores of BC particles. This observation was also supported by negligible adsorption and precipitation of $\mathrm{Fe}^{2+} / \mathrm{Fe}^{3+}$ and iron hydroxides on $\mathrm{BC}$ surface or into interior pores of $\mathrm{BC}$ particles respectively. Precipitation of $\mathrm{Fe}^{2+}$ and $\mathrm{Fe}^{3+}$, rather than adsorption, is responsible for the removal of $\mathrm{Fe}^{2+}$ and $\mathrm{Fe}^{3+}$ by $\mathrm{BC}$. Moreover, precipitates of iron hydroxides cannot be reduced to NZVI by $\mathrm{NaBH}_{4}$. In addition to SEM or P-TEM, therefore, C-TEM is a potential technique which should be employed to characterize the interior morphology of $\mathrm{NZVI} / \mathrm{BC}$ for better understanding the reduction mechanisms and performance of contaminants by NZVI/BC.

Keywords: Nanoscale zero-valent iron, Biochar, Cross-sectional TEM, Interior morphology, Biochar supported nanoscale zero-valent iron, SEM 


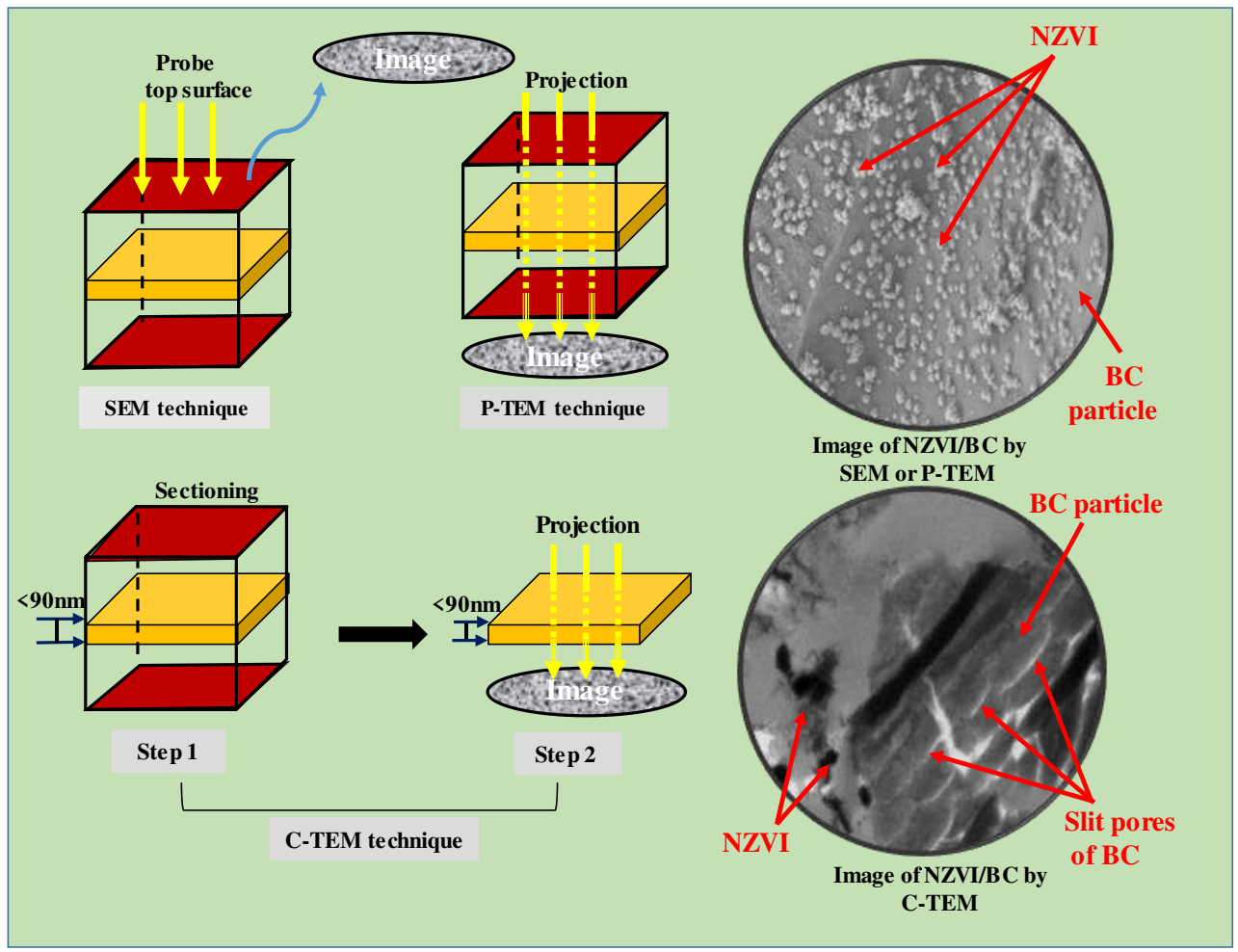




\section{Introduction}

Nanoscale zero-valent iron (NZVI), as an environmental friendly material has been widely used in recent decades to reduce contaminants such as $\mathrm{Cr}(\mathrm{VI}), \mathrm{As}(\mathrm{V})$, nitrates, and chlorinated organics ${ }^{1-6}$. Biochar (BC) supported NZVI (NZVI/BC), prepared commonly by liquid-phase reduction method using sodium borohydride $\left(\mathrm{NaBH}_{4}\right)$ as reducing agent, has better ability in reducing pollutants than $\mathrm{NZVI}^{7-9}$. The oxidation and agglomeration of NZVI can be effectively suppressed by BC, therefore, NZVI's surface energy and reduction activity can be maintained ${ }^{5,10-12}$. In previous studies $^{13-16}$, by scanning electron microscopy (SEM) and plan transmission electron microscopy (P-TEM) techniques, it was observed that NZVI particles were loaded on the surface or in the interior pores of $\mathrm{BC}$ particles, which is responsible for the improved reduction ability of $\mathrm{NZVI}^{17-19}$. Several possible ways were suggested to interpret the loading of NZVI on BC surface or in $\mathrm{BC}$ interior pores ${ }^{15,20-23}$ (i) $\mathrm{Fe}^{2+} / \mathrm{Fe}^{3+}$ ions are adsorbed on surface or into interior pores of $\mathrm{BC}$ and then be reduced to $\mathrm{NZVI}$ by $\mathrm{NaBH}_{4}$; (ii) $\mathrm{Fe}^{2+} / \mathrm{Fe}^{3+}$ ions are hydrolyzed into precipitates of iron hydroxide, and then deposited on surface or into interior pores of $\mathrm{BC}$ particles for reduction to $\mathrm{NZVI}$ by $\mathrm{NaBH}_{4}$; (iii) $\mathrm{Fe}^{2+} / \mathrm{Fe}^{3+}$ ions are reduced to NZVI by $\mathrm{NaBH}_{4}$ in solutions and then deposited on BC surface or into the interior pores of BC particles.

SEM and P-TEM are widely used electron microscopy techniques with high resolution and high magnification to visualize the morphology of $\mathrm{NZVI/BC}{ }^{24-26}$. However, by collecting secondary electrons reflected from sample surface, SEM technique can only visualize the sample top surface but not the interior structures ${ }^{27,28}$. 
66 For P-TEM technique, the accumulated signals of the sample from top to bottom

67 including the interior structures can be obtained by collecting electrons through the

68 sample ${ }^{29}$. However, the accumulated signals of P-TEM are difficult to explore the

69 interior structure of samples clearly because the interior structure signals are actually

70 covered by the electron signals of top and bottom surfaces, i.e., there is a problem of

71 superimposition for P-TEM technique ${ }^{30,31}$. Therefore, both of SEM and P-TEM

72 technique cannot explore the interior structure signals of NZVI/BC particle clearly for

73 understanding the underlying improved reduction mechanisms of contaminants by

$74 \quad \mathrm{NZVI} / \mathrm{BC}$.

75 Cross-sectional TEM (C-TEM) technique, first reported in $1974^{32}$, is conducted 76 through directly observing the inner ultra-thin slices (with thickness less than $100 \mathrm{~nm}$ )

77 of samples using P-TEM technique. This technique can eliminate the problem of 78 superimposition of P-TEM technique by avoiding the interfering of the sample surface 79 signals, and thus, obtain the pure signals of interior structure of the sample ${ }^{33-35}$.

80 Therefore, C-TEM technique has been applied widely in characterizing of solid 81 materials such as bulk heterojunction films ${ }^{36,37}$, biochar $^{38}$, and activated carbons ${ }^{39}$ in 82 previous studies. In this study, therefore, C-TEM technique was firstly employed to 83 directly identify the interior structures of NZVI/BC, especially the micro locations of 84 NZVI in NZVI/BC particles, for exploring the underlying reduction mechanisms of $85 \quad \mathrm{NZVI} / \mathrm{BC}$ for contaminants reduction. 


\section{Results and Discussion}

The surface morphology of BC particles observed by SEM technique is relatively smooth in lamellar structure (Figure 1a), with abundant irregular pores (Figure 1b). However, in C-TEM images (Figure 1c and 1d), the slices of BC particles are in the sheet-like shape, showing abundant slit pores in uniform pore size. Bulk NZVI particles in SEM (Figure 2a) and C-TEM (Figure 2b) images are roughly spherical and aggregated significantly to a chain-like structure, which should be attributed to the intrinsic magnetic attraction between the NZVI particles ${ }^{4,5,12,40,41}$. There are a lot of chain-like clusters and roughly spherical particles dispersed on BC surface in SEM images of NZVI/BC (Figure 3a and 3b). These chain-like clusters and roughly spherical particles on the surface of NZVI/BC are also observed in SEM images of bulk NZVI particles (Figure 2a) and in SEM images of NZVI/BC in previous studies ${ }^{11,18,40,42}$, which should be attributed to NZVI particles. EDX spectrum of NZVI/BC shows that the main elemental composition of $\mathrm{NZVI} / \mathrm{BC}$ is $\mathrm{C}, \mathrm{Fe}$ and $\mathrm{O}$ (Figure 3c). The homogeneous distribution of $\mathrm{C}$ and Fe was also verified in SEM elemental mapping of NZVI/BC (Figure S2). NZVI particles formed in NZVI/BC are identified by the characteristic peak at $44.7^{\circ}$ (Figure $3 \mathrm{~d}$ ) of XRD pattern of NZVI/BC. NZVI particles formed and dispersed on the surface of NZVI/BC were also observed in P-TEM images of NZVI/BC in previous studies ${ }^{19,22}$. However, in C-TEM images of NZVI/BC (Figure 4a), NZVI particles are existed isolated from BC particles rather than attached on the surface of BC particles. The distinguished observations in C-TEM images of NZVI/BC from that in SEM and P-TEM images of NZVI/BC, could be attributed to the top surface 
108 view of SEM technique ${ }^{27,29}$ and the superimposition problem of P-TEM technique ${ }^{30 \text {, }}$

109 31. Thus, both of SEM and P-TEM techniques cannot explore the interior structure

110 signals of NZVI/BC particles. Moreover, NZVI particles are not observed in interior

111 slit pores of BC particles (Figure 4b), i.e., NZVI particles cannot be embedded into the

112 interior pores of $\mathrm{BC}$ particles. As reported in the previous literatures ${ }^{11,43,44}$, the average

113 particle size of NZVI on NZVI/BC is about 30 100 nm. In this study, the particle size

114 of NZVI in NZVI/BC is in the range of 40-180 nm (Figure 3b). However, BC is

115 basically composed of micropores and mesopores with average diameter less than 10

$116 \mathrm{~nm}{ }^{13,38,45}$. The $\mathrm{N}_{2}$ adsorption-desorption isotherm and pore size distribution of $\mathrm{BC}$ in

117 this study are shown in Figure S3. The specific surface and average pore size of BC are

$118579.15 \mathrm{~m}^{2} / \mathrm{g}$ and $2.486 \mathrm{~nm}$, respectively. Therefore, NZVI particles cannot enter into

119 interior pores of $\mathrm{BC}$ particles, showing the clean and slit pores without any iron particles

120 in C-TEM images of nZVI/BC (Figure 4). In addition, the surface morphology of

121 NZVI/BC in SEM images (Figure 3a and 3b) and inner cross section structure of

$122 \mathrm{NZVI} / \mathrm{BC}$ in C-TEM images (Figure 4) as well as the XRD pattern (Figure 3d) of

$123 \mathrm{NZVI} / \mathrm{BC}$ are similar to that of NZVI+BC (Figure 3d and Figure 5), the sample mixed

124 from NZVI and $\mathrm{BC}$ directly. Therefore, $\mathrm{NZVI/BC}$ is similar to $\mathrm{NZVI+BC}$, without

125 attachment of NZVI on BC surface or into BC interior pores, i.e., the better reduction

126 ability of NZVI/BC for contaminants than NZVI cannot be interpreted by the

127 attachment of NZVI on BC surface or into BC interior pores.

128 Adsorption of $\mathrm{Fe}^{2+}$ or $\mathrm{Fe}^{3+}$ ions on $\mathrm{BC}$ and then reduction of adsorbed $\mathrm{Fe}^{2+}$ or $\mathrm{Fe}^{3+}$

129 ions by $\mathrm{NaBH}_{4}$ was proposed as a possible way to load NZVI on BC surface or in BC 
130 interior pores ${ }^{15,21,22}$. However, we observed that the removal curves of $\mathrm{Fe}^{3+}$ in the

131 presence of $\mathrm{BC}$ under various $\mathrm{pH}$ were overlapped with the precipitation curve of $\mathrm{Fe}^{3+}$

132 without BC (Figure 6a and 6b). Moreover, removal curves of $\mathrm{Fe}^{3+}$ were independent of

133 the dosage of $\mathrm{BC}(20$ and $200 \mathrm{mg})$ in Figure $6 \mathrm{a}$ or initial concentration of $\mathrm{Fe}^{3+}(50$ and

$134150 \mathrm{mg} / \mathrm{L})$ in Figure 6b. Therefore, the removal of $\mathrm{Fe}^{3+}$ ions in the presence of $\mathrm{BC}$

135 should be attributed primarily to precipitation by formation of $\mathrm{Fe}(\mathrm{OH})_{3}$ rather than

136 adsorption on $\mathrm{BC}^{46}$. Although the removal curve of $\mathrm{Fe}^{2+}$ was not overlapped with the

137 precipitation curve of $\mathrm{Fe}^{2+}$ without $\mathrm{BC}$ (Figure 6c), it was overlapped with the

138 precipitation curve of $\mathrm{Fe}^{3+}$ without $\mathrm{BC}$ (Figure 6d), implying that the oxidation of $\mathrm{Fe}^{2+}$

139 to $\mathrm{Fe}^{3+}$ and then the precipitation of $\mathrm{Fe}^{3+}$ may be responsible for the removal of $\mathrm{Fe}^{2+}$

140 with BC. In order to check this hypothesis, four different points (A, B, C, D) were

141 chosen to determine the mass of $\mathrm{Fe}^{2+}$ and $\mathrm{Fe}^{3+}$ in supernatants and solids, respectively

142 (Figure 6c). Species distribution of $\mathrm{Fe}^{2+}$ and $\mathrm{Fe}^{3+}$ in supernatant and solids are listed in

143 Table S1. Oxidation of $\mathrm{Fe}^{2+}$ to $\mathrm{Fe}^{3+}$ with or without BC were observed (Table S1). In

144 the presence of $\mathrm{BC}$ and higher $\mathrm{pH}$, more $\mathrm{Fe}^{2+}$ were oxidized to $\mathrm{Fe}^{3+}$ (Table $\mathrm{S} 1$ ).

145 Therefore, the oxidation of $\mathrm{Fe}^{2+}$ to $\mathrm{Fe}^{3+}$ occurred in batch experiment for $\mathrm{Fe}^{2+}$ by $\mathrm{BC}$.

146 Characteristic peak of NZVI was not observed in XRD diffraction pattern of NZVI/BC*,

147 a sample prepared by removing excessive free $\mathrm{Fe}^{2+}$ in $\mathrm{Fe}^{2+} / \mathrm{BC}$ system before adding

$148 \mathrm{NaBH}_{4}$ (Figure 3d), indicating almost no $\mathrm{Fe}^{2+}$ or $\mathrm{Fe}^{3+}$ adsorbed on BC. Moreover, the

149 C-TEM diagrams of NZVI/BC* were similar to that of BC (Figures S4), indicating that

150 no black NZVI particles observed in NZVI/BC, i.e., no $\mathrm{Fe}^{2+}$ or $\mathrm{Fe}^{3+}$ adsorption on $\mathrm{BC}$ 
151 observed. Therefore, $\mathrm{Fe}^{2+}$ and $\mathrm{Fe}^{3+}$ cannot be fixed on $\mathrm{BC}$ surface or in interior pores

152 through adsorption to form NZVI on BC by reduction using $\mathrm{NaBH}_{4}$.

153 Forming of $\mathrm{Fe}(\mathrm{OH})_{2}$ or $\mathrm{Fe}(\mathrm{OH})_{3}$ precipitates, deposited on $\mathrm{BC}$ and then reduced

154 to NZVI by $\mathrm{NaBH}_{4}$ was proposed as another possible way to load NZVI on BC surface

155 or in $\mathrm{BC}$ interior pores ${ }^{20,22}$. However, depositing of $\mathrm{Fe}(\mathrm{OH})_{2}$ or $\mathrm{Fe}(\mathrm{OH})_{3}$ precipitates on

156 the surface or in the interior pores of BC particles were not observed in C-TEM images

157 of NZVI/BC* (Figure S4), showing that the surface and pores of NZVI/BC* are clean

158 and similar to that of BC (Figure S4). Moreover, NZVI can be obtained by reducing

159 iron salt with $\mathrm{NaBH}_{4}$ rather than hydroxide ${ }^{4,47}$, i.e., $\mathrm{Fe}(\mathrm{OH})_{2}$ or $\mathrm{Fe}(\mathrm{OH})_{3}$ cannot be

160 reduced to NZVI by $\mathrm{NaBH}_{4}$. For example, the suspensions of dark green $\mathrm{Fe}(\mathrm{OH})_{2}$

161 precipitates and reddish brown $\mathrm{Fe}(\mathrm{OH})_{3}$ precipitates (Figure 7a), prepared from $\mathrm{Fe}^{2+}$

162 and $\mathrm{Fe}^{3+}$ respectively via chemical precipitation, are not changed in color after dropping

$163 \mathrm{NaBH}_{4}$ (Figure 7b), i.e., No black ZVI particles formed after reduction treatment of

$164 \mathrm{Fe}(\mathrm{OH})_{2}$ and $\mathrm{Fe}(\mathrm{OH})_{3}$ precipitates with $\mathrm{NaBH}_{4}$. The characteristic peak of NZVI was

165 not observed in XRD diffraction patterns of the dried solid samples collected from

$166 \mathrm{NaBH}_{4}$ treated $\mathrm{Fe}(\mathrm{OH})_{2}$ and $\mathrm{NaBH}_{4}$ treated $\mathrm{Fe}(\mathrm{OH})_{3}$ (Figure 3d), indicating NZVI

167 cannot be obtained from $\mathrm{Fe}(\mathrm{OH})_{2}$ and $\mathrm{Fe}(\mathrm{OH})_{3}$ precipitates by reduction using $\mathrm{NaBH}_{4}$.

168 Therefore, NZVI cannot be loaded on $\mathrm{BC}$ via depositing of $\mathrm{Fe}(\mathrm{OH})_{2} / \mathrm{Fe}(\mathrm{OH})_{3}$

169 precipitates on surface or into interior pores of $\mathrm{BC}$ particles as well as reduction of

$170 \mathrm{Fe}(\mathrm{OH})_{2} / \mathrm{Fe}(\mathrm{OH})_{3}$ precipitates to $\mathrm{NZVI}$ by $\mathrm{NaBH}_{4}$.

171 Except for loading of NZVI on the surface or into the interior pores of BC, smaller

172 size of NZVI in NZVI/BC was proposed to interpret the better reduction performance 
173 of contaminants by NZVI/BC than bulk NZVI ${ }^{22,40,48}$. Smaller-sized NZVI is more

174 reactive, which can be attributed to its higher surface area-to-volume ration and stronger

175 quantum effects ${ }^{4,6,11}$. In this study, bulk NZVI particles are aggregated into micron-

176 size particles (Figure 2), which is consistent with the previous reports ${ }^{6,40,49}$. However,

177 the particle size of NZVI in NZVI/BC is in the range of $40-180 \mathrm{~nm}$ (Figure $3 \mathrm{~b}$ and

178 Figure 4), much smaller than that of bulk NZVI (Figure 2), implying that the 179 agglomeration of NZVI particles is effectively alleviated by $\mathrm{BC}^{10,22}$. The alleviation of

180 NZVI agglomeration was also observed in sample NZVI+BC, showing that the particle

181 size of NZVI in NZVI+BC is in the range of 50-220 nm (Figure 5). Therefore, the

182 smaller size of NZVI in NZVI/BC than that of bulk NZVI could be possibly responsible

183 for the better reduction performance of contaminants by NZVI/BC than bulk NZVI ${ }^{10-}$ $184 \quad 12$.

\section{3. Conclusion and outlook}

186 Employing C-TEM technique for liquid reduction method prepared NZVI/BC, it

187 was observed in this study that NZVI particles are existed isolated from BC particles in

$188 \mathrm{NZVI} / \mathrm{BC}$, rather than attached on surface or in interior pores of BC particles that was

189 observed in previous study by SEM and P-TEM techniques. This observation was also

190 supported by the negligible adsorption of $\mathrm{Fe}^{2+} / \mathrm{Fe}^{3+}$ and the negligible attachment of

$191 \mathrm{Fe}(\mathrm{OH})_{2} / \mathrm{Fe}(\mathrm{OH})_{3}$ precipitates on $\mathrm{BC}$ surface or interior pore structure of $\mathrm{BC}$ particles,

192 as well as the negligible reduction of $\mathrm{Fe}(\mathrm{OH})_{2} / \mathrm{Fe}(\mathrm{OH})_{3}$ to NZVI by $\mathrm{NaBH}_{4}$. Therefore,

193 both of the widely used SEM and P-TEM techniques have difficulty in observing the

194 inner structure of NZVI/BC. In addition to SEM and P-TEM, C-TEM is a useful 
195 technique which should be employed to characterize the interior morphology of

196 NZVI/BC and other porous materials supported NZVI for better exploring the

197 underlying improved reduction mechanisms of contaminants by porous materials

198 supported NZVI. The smaller size of NZVI particles in NZVI/BC than bulk NZVI 199 rather than the attachment of NZVI particles on surface or into interior pores of BC 200 particles in NZVI/BC, could be responsible for the better reduction performance of 201 contaminants by NZVI/BC than bulk NZVI.

211 sieve, were packed in crucibles, covered with lids, and then, placed in a muffle furnace,

212 pyrolyzed at $700^{\circ} \mathrm{C}$ for $6 \mathrm{~h}$. The prepared $\mathrm{BC}$ was washed with $1 \mathrm{~mol} / \mathrm{L} \mathrm{HCl}(\mathrm{m} / \mathrm{v}=0.1$ $213 \mathrm{~g} / \mathrm{mL}$ ) by stirring for $24 \mathrm{~h}$ to remove impurities and then rinsed using deionized (DI)

214 water to neutral $\mathrm{pH}$. The obtained $\mathrm{BC}$ sample was dried overnight at $80^{\circ} \mathrm{C}$ in an oven 215 for usage.

Ferrous sulfate heptahydrate $\left(\mathrm{FeSO}_{4} \cdot 7 \mathrm{H}_{2} \mathrm{O}, 97 \%\right)$, sodium borohydride $\left(\mathrm{NaBH}_{4}\right.$, 98\%), and hydroxylamine hydrochloride $\left(\mathrm{NH}_{2} \mathrm{OH} \cdot \mathrm{HCl}, 99 \%\right)$ were supplied by Sinopharm Group Chemical Reagent, China. Ferric chloride hexahydrate $\left(\mathrm{FeCl}_{3} \cdot 6 \mathrm{H}_{2} \mathrm{O}\right.$, 99\%) was obtained from Aladdin Reagent Corporation.

\subsection{Preparation of $\mathrm{BC}$ and NZVI materials}

BC was prepared from wood chips (Ningbo, Zhejiang, China) by oxygen-limited pyrolysis method ${ }^{50}$. Briefly, dried wood chips, grounded to pass through a $0.15 \mathrm{~mm}$ 
Bulk NZVI was synthesized using the liquid-phase reduction method ${ }^{11,12,51}$.

217 Briefly, under nitrogen atmosphere, $100 \mathrm{~mL} \mathrm{NaBH}_{4}$ solution $(1.2 \mathrm{~mol} / \mathrm{L})$ was dropped

218 (1-2 drops/s) into $100 \mathrm{~mL} \mathrm{FeSO}_{4}$ solution (0.44 mol/L) with stirring. The black NZVI

219 particles were separated by centrifugation for $5 \mathrm{~min}$ at $3000 \mathrm{rpm}$. Then, NZVI particles

220 were washed with deoxygenated DI water, followed by ethanol, and finally dried in a

221 vacuum oven at $60^{\circ} \mathrm{C}$ for $12 \mathrm{~h}$.

$\mathrm{NZVI/BC}$ was prepared according to the procedures reported in the previous

223 literature ${ }^{52}$. Under nitrogen atmosphere, $100 \mathrm{~mL}$ of $0.44 \mathrm{~mol} / \mathrm{L} \mathrm{FeSO}_{4}$ solution was 224 mixed with $5.0 \mathrm{~g} \mathrm{BC}$ for $3 \mathrm{~h}$. Then, $100 \mathrm{~mL}$ of $1.2 \mathrm{~mol} / \mathrm{L} \mathrm{NaBH}_{4}$ was added dropwise 225 into the mixture. After reaction, NZVI/BC was collected by centrifugation at $3000 \mathrm{rpm}$ 226 for 5 min, washed with deoxygenated DI water and ethanol, and dried in a vacuum oven $227\left(60^{\circ} \mathrm{C}, 12 \mathrm{~h}\right)$. $\mathrm{NZVI} / \mathrm{BC}^{*}$ was prepared as follows. $100 \mathrm{~mL}$ of $0.44 \mathrm{~mol} / \mathrm{L} \mathrm{FeSO}_{4}$ solution was mixed with $5.0 \mathrm{~g} \mathrm{BC}$ under nitrogen atmosphere for $24 \mathrm{~h}$. Then the solid was collected

230 by centrifugation at $3000 \mathrm{rpm}$ for $5 \mathrm{~min}$ and followed by washing with deoxygenated

231 DI water for three times to remove excess free $\mathrm{Fe}^{2+}$ that not adsorbed on $\mathrm{BC}$. Under 232 nitrogen atmosphere, $100 \mathrm{~mL}$ of $1.2 \mathrm{~mol} / \mathrm{L} \mathrm{NaBH}_{4}$ was added dropwise into the 233 suspension of $\mathrm{BC}$ which was pretreated with $\mathrm{FeSO}_{4}$ solutions. Then, by centrifugation 234 at $3000 \mathrm{rpm}$ for $5 \mathrm{~min}$, washed with deoxygenated DI water and ethanol, and dried in a 235 vacuum oven at $60^{\circ} \mathrm{C}$ for $12 \mathrm{~h}, \mathrm{nZVI} / \mathrm{BC}^{*}$ was collected.

236 NZVI+BC was prepared directly by mixing BC and NZVI particles. Briefly, $1.0 \mathrm{~g}$ 237 BC and $0.5 \mathrm{~g}$ NZVI were mixed in $30 \mathrm{~mL}$ ethanol in a beaker and dispersed by 
238 ultrasonic cell breaker (SCIENTZ-II D) for $10 \min \left(20^{\circ} \mathrm{C}, 570 \mathrm{~W}\right)$. Then, the mixed

239 NZVI+BC sample was separated by centrifugation at $3000 \mathrm{rpm}$ for $5 \mathrm{~min}$ and dried in 240 a vacuum oven $\left(60^{\circ} \mathrm{C}, 12 \mathrm{~h}\right)$.

\section{4.3. Characterization of BC and NZVI materials}

242 The inner structure information of BC and NZVI materials was observed by C-

243 TEM technique directly ${ }^{38,39}$. These samples were firstly embedded into embedding

244 agent, i.e., spurr resin, which is a mixture of $10 \mathrm{~g}$ vinyl cyclohexene dioxide (ERL 4221),

$2458 \mathrm{~g}$ diglycidyl ether of polypropylene glycol (DER 736), $25 \mathrm{~g}$ nonenyl succinic 246 anhydride (NSA) and $0.3 \mathrm{~g}$ 2-dimethylaminoethanol (DMAE), purchased from SPI247 Chem Supplies. Then, spurr resin embedded samples were heated at $70^{\circ} \mathrm{C}$ for $12 \mathrm{~h}$, and 248 cut into ultra-thin slices with thickness less than $90 \mathrm{~nm}$ by ultramicrotome (Leica, 249 EMUC7, Germany) equipped with diamond knife (Figure S1). The slices were finally 250 collected on copper mesh grids for observation of transmission electron microscopy 251 (TEM) (JEM1200, JEOL, Japan).

252 X-ray diffraction patterns of samples were obtained by an X-ray diffractometer 253 (XRD, Philips, Netherlands) equipped with a $\mathrm{CuK} \alpha$ radiation source and scanned at a 254 speed of $2^{\circ}$ per min. Surface morphologies of samples were examined by using a field 255 emission SEM (FE-SEM) (SIRON, FEI, Netherlands) equipped with an energy 256 dispersive spectroscopy (Oxford Inca EDS) at a voltage of $25.0 \mathrm{KV}$.

\subsection{Batch experiments for $\mathrm{Fe}^{2+}$ and $\mathrm{Fe}^{3+}$ by $\mathrm{BC}$}

$$
\mathrm{Fe}^{2+} \text { and } \mathrm{Fe}^{3+} \text { solution was prepared from } \mathrm{FeSO}_{4} \cdot 7 \mathrm{H}_{2} \mathrm{O} \text { and } \mathrm{FeCl}_{3} \cdot 6 \mathrm{H}_{2} \mathrm{O}
$$

259 respectively. Batch experiment of $\mathrm{Fe}^{2+}$ and $\mathrm{Fe}^{3+}$ was conducted in $22 \mathrm{~mL}$ screw cap vials 
with a total solution volume of $20 \mathrm{~mL}$ sealed with Teflon-coated septa under ambient

261 temperature $\left(25^{\circ} \mathrm{C}\right)$. Briefly, $20 \mathrm{mg}$ or $200 \mathrm{mg} \mathrm{BC}$ was added into vials having $18 \mathrm{~mL}$

262 background solution with various $\mathrm{pH}$ value, prepared from DI water with $0.01 \mathrm{~mol} / \mathrm{L}$

$263 \mathrm{HCl}$ and $\mathrm{NaOH}$. Then, $2 \mathrm{~mL} \mathrm{Fe}^{2+}$ or $\mathrm{Fe}^{3+}$ solution $(500 \mathrm{mg} / \mathrm{L}$ or $1500 \mathrm{mg} / \mathrm{L})$, was added

264 into the vials to give the initial $\mathrm{Fe}^{2+}$ or $\mathrm{Fe}^{3+}$ concentration of $50 \mathrm{mg} / \mathrm{L}$ or $150 \mathrm{mg} / \mathrm{L}$,

265 respectively. The vials were capped and transferred to a horizontal shaker (DHZ-D) at

$266150 \mathrm{rpm}$ for $48 \mathrm{~h}$. After centrifugation at $3000 \mathrm{rpm}$ for $5 \mathrm{~min}$, supernatant was taken

267 from vials, and filtered with a $0.22 \mu \mathrm{m}$ needle filter to remove the solid. The $\mathrm{pH}$ value

268 of supernatant was measured using a glass $\mathrm{pH}$ electrode (Mettler Toledo). The

269 concentration of $\mathrm{Fe}^{2+}$ iron in supernatant was determined by UV-spectrophotometer

270 (UV-2450, Shimadzu, Japan) with 1,10-phenanthroline spectrophotometric method at

271 a maximum wavelength of $510 \mathrm{~nm}^{53}$. For measurement of $\mathrm{Fe}^{3+}, \mathrm{Fe}^{3+}$ in supernatant was

272 reduced to $\mathrm{Fe}^{2+}$ firstly by $\mathrm{NH}_{2} \mathrm{OH} \cdot \mathrm{HCl}^{54}$, and then, determined by UV-

273 spectrophotometer with 1,10-phenanthroline spectrophotometric method ${ }^{53}$.

274 The removal efficiency of $\mathrm{Fe}^{2+}$ or $\mathrm{Fe}^{3+}$ was calculated by Equation 1:

$$
\mathrm{R} \%=\left(C_{0}-C \mathrm{e}\right) / C_{0} * 100 \%
$$

276 Where $C_{0}(\mathrm{mg} / \mathrm{L})$ is the initial concentration of $\mathrm{Fe}^{2+}$ or $\mathrm{Fe}^{3+}$ in solution, $C \mathrm{e}(\mathrm{mg} / \mathrm{L})$

277 is the equilibrium concentration of $\mathrm{Fe}^{2+}$ or $\mathrm{Fe}^{3+}$ in solution.

278 4.5. Precipitation of $\mathrm{Fe}^{2+}$ and $\mathrm{Fe}^{3+}$ in aqueous

279 Precipitation of $\mathrm{Fe}^{2+}$ and $\mathrm{Fe}^{3+}$ was also conducted in $22 \mathrm{~mL}$ screw cap vials. 18 $280 \mathrm{~mL}$ background water at various $\mathrm{pH}$, prepared from $\mathrm{DI}$ water with $0.01 \mathrm{~mol} / \mathrm{L} \mathrm{HCl}$ and $281 \mathrm{NaOH}$, and $2 \mathrm{~mL} \mathrm{Fe} \mathrm{Fe}^{2+}$ or $\mathrm{Fe}^{3+}$ solution $(500 \mathrm{mg} / \mathrm{L})$ were mixed in the vials, i.e., the 
282 initial $\mathrm{Fe}^{2+}$ or $\mathrm{Fe}^{3+}$ concentration in vials was $50 \mathrm{mg} / \mathrm{L}$. The vials were capped and 283 transferred to a horizontal shaker (DHZ-D) at $150 \mathrm{rpm}$ for $48 \mathrm{~h}$ under ambient 284 temperature $\left(25^{\circ} \mathrm{C}\right)$. After centrifugation at $3000 \mathrm{rpm}$ for $5 \mathrm{~min}, \mathrm{pH}$ value and 285 equilibrium concentration of $\mathrm{Fe}^{2+}$ or $\mathrm{Fe}^{3+}$ in supernatant were measured with glass $\mathrm{pH}$ 286 electrode (Mettler Toledo) and UV-spectrophotometer (UV-2450, Shimadzu, Japan), 287 respectively ${ }^{53,54}$.

288 4.6. Reduction of $\mathrm{Fe}(\mathrm{OH})_{2}$ and $\mathrm{Fe}(\mathrm{OH})_{3}$ by $\mathrm{NaBH}_{4}$

289 For reduction experiments of $\mathrm{Fe}(\mathrm{OH})_{2}$ or $\mathrm{Fe}(\mathrm{OH})_{3}$ precipitates by $\mathrm{NaBH}_{4}, 10 \mathrm{~mL}$ $290 \quad 0.25 \mathrm{M} \mathrm{Fe}^{2+}$ or $\mathrm{Fe}^{3+}$ solution and $10 \mathrm{~mL} 1.0 \mathrm{M} \mathrm{NaOH}$ solution were mixed and then 291 centrifuged at $3000 \mathrm{rpm}$ for 5 min to collect $\mathrm{Fe}(\mathrm{OH})_{2}$ or $\mathrm{Fe}(\mathrm{OH})_{3}$ precipitates. The 292 collected $\mathrm{Fe}(\mathrm{OH})_{2}$ or $\mathrm{Fe}(\mathrm{OH})_{3}$ precipitate was washed with deoxidizing DI water for 293 three times to remove excessive $\mathrm{Fe}^{2+}$ or $\mathrm{Fe}^{3+}$ ions. Before reduction by $\mathrm{NaBH}_{4}$, another $29420 \mathrm{~mL}$ deoxidizing DI water was added to redisperse $\mathrm{Fe}(\mathrm{OH})_{2}$ or $\mathrm{Fe}(\mathrm{OH})_{3}$ precipitates. 295 Then, $20 \mathrm{~mL} 1.0 \mathrm{M} \mathrm{NaBH}_{4}$ was added dropwise under nitrogen atmosphere to reduce 296 the precipitates. After reduction reaction, solid product was collected by centrifugation 297 at $3000 \mathrm{rpm}$ for $5 \mathrm{~min}$, washed with deoxidizing DI water and ethanol, and finally dried 298 in a vacuum oven at $60^{\circ} \mathrm{C}$ for $12 \mathrm{~h}$. 


\section{Reference}

305 1. Liu, S. C. et al. Study on influencing factors and mechanism of removal of Cr(VI)

306 from soil suspended liquid by bentonite-supported nanoscale zero-valent iron. Scientific

307 Reports. 10, $8831(2020)$

308 2. Ahmad, M. et al. Turning date palm waste into carbon nanodots and nano zerovalent

309 iron composites for excellent removal of methylthioninium chloride from water.

310 Scientific Reports. 10, 16125 (2020).

311 3. Gil-Díaz, M.; Álvarez, M. A.; Alonso, J. \& Lobo. M. C. Effectiveness of nanoscale 312 zero-valent iron for the immobilization of $\mathrm{Cu}$ and/or $\mathrm{Ni}$ in water and soil samples.

313 Scientific Reports. 10, 15927 (2020).

314 4. Wang, C. B. \& Zhang, W. X. Synthesizing nanoscale iron particles for rapid and 315 complete dechlorination of TCE and PCBs. Environ. Sci. Technol. 31, 2154-2156 316 (1997).

317 5. Zhao, X.; Liu, W.; Cai, Z.; Han, B.; Qian, T. \& Zhao, D. An overview of preparation 318 and applications of stabilized zero-valent iron nanoparticles for soil and groundwater 319 remediation. Water Res. 100, 245-266 (2016).

320 6. Zou, Y. et al. Environmental remediation and application of nanoscale zero-valent 321 iron and its composites for the removal of heavy metal ions: a review. Environ. Sci. 322 Technol. 50, $7290-7304$ (2016).

323 7. Mackenzie, K.; Bleyl, S.; Kopinke, F. D.; Doose, H. \& Bruns, J. Carbo-Iron as 324 improvement of the nanoiron technology: From laboratory design to the field test. Sci. 325 Total. Environ. 563, 641-648 (2016).

326 8. Diao, Z. H. et al. Insights into the simultaneous removal of $\mathrm{Cr}^{6+}$ and $\mathrm{Pb}^{2+}$ by a novel 327 sewage sludge-derived biochar immobilized nanoscale zero valent iron: Coexistence 328 effect and mechanism. Sci. Total. Environ. 642, 505-515 (2018).

329 9. Qian, L. B. et al. Field demonstration of enhanced removal of chlorinated solvents in 330 groundwater using biochar-supported nanoscale zero-valent iron. Sci. Total. Environ. $331 \quad 698,134215$ (2020). 
332 10. Dong, H. R. et al. Stabilization of nanoscale zero-valent iron (nZVI) with modified 333 biochar for $\mathrm{Cr}(\mathrm{VI})$ removal from aqueous solution. J. Hazard. Mater. 332, 79-86 (2017).

334 11. Liu, C. M.; Diao, Z. H.; Huo, W. Y.; Kong, L. J. \& Du, J. J. Simultaneous removal 335 of $\mathrm{Cu}^{2+}$ and bisphenol A by a novel biochar-supported zero valent iron from aqueous 336 solution: synthesis, reactivity and mechanism. Environ. Pollut. 239, 698-705 (2018).

337 12. Xu, J. et al. Iron and Sulfur Precursors Affect Crystalline Structure, Speciation, and 338 Reactivity of Sulfidized Nanoscale Zerovalent Iron. Environ. Sci. Technol. 54, 13294$33913303(2020)$.

340 13. Dong, H. R. et al. Removal of trichloroethylene by biochar supported nanoscale 341 zero-valent iron in aqueous solution. Sep. Purif. Technol. 188, 188-196 (2017).

342 14. Liati, A. et al. Electron microscopic study of soot particulate matter emissions from 343 aircraft turbine engines. Environ. Sci. Technol. 48, 10975-10983 (2014).

344 15. Zhu, S. et al. Magnetic nanoscale zerovalent iron assisted biochar: interfacial 345 chemical behaviors and heavy metals remediation performance. ACS Sustain. Chem. 346 Eng. 5, 9673-9682 (2017).

347 16. Wei, A. L.; Ma, J.; Chen, J. J.; Zhang, Y.; Song, J. X. \& Yu, X. Y. Enhanced nitrate 348 removal and high selectivity towards dinitrogen for groundwater remediation using 349 biochar-supported nano zero-valent iron. Chem. Eng. J. 353, 595-605 (2018).

350 17. Liu, W. J.; Jiang, H. \& Yu, H. Q. Development of biochar-based functional 351 materials: toward a sustainable platform carbon material. Chem. Rev. 115, 12251-12285 352 (2015).

353 18. Ahmed, M. B. et al. Nano-Fe-0 immobilized onto functionalized biochar gaining 354 excellent stability during sorption and reduction of chloramphenicol via transforming 355 to reusable magnetic composite. Chem. Eng. J. 322, 571-581 (2017).

356 19. Shang, J. G.; Zong, M. Z.; Yu, Y.; Kong, X. R.; Du, Q. \& Liao, Q. J. H. Removal 357 of chromium (VI) from water using nanoscale zerovalent iron particles supported on 358 herb-residue biochar. J. Environ. Manage. 197, 331-337 (2017). 
20. Chen, W.; Pan, L.; Chen, L.; Wang, Q. \& Yan, C. Dechlorination of

360 hexachlorobenzene by nano zero-valent iron/activated carbon composite: iron loading,

361 kinetics and pathway. Rsc Adv. 4, 46689-46696 (2014).

362 21. Qian, L. B. et al. Nanoscale zero-valent iron supported by biochars produced at 363 different temperatures: synthesis mechanism and effect on $\mathrm{Cr}(\mathrm{VI})$ removal. Environ. 364 Pollut. 223, 153-160 (2017).

365 22. Wang, S. S. et al. Biochar-supported nZVI (nZVI/BC) for contaminant removal 366 from soil and water: A critical review. J. Hazard. Mater. 373, 820-834 (2019).

367 23. Zhang, D. J. et al. Enhanced nitrobenzene reduction by modified biochar supported 368 sulfidated nano zerovalent iron: Comparison of surface modification methods. Sci. 369 Total. Environ. 694, 133701 (2019).

370 24. Maillard, M.; Giorgio, S. \& Pileni, M. P. Silver nanodisks. Adv. Mater. 14, 1084$3711086(2002)$.

372 25. Cao, G. H.; Simon, P.; Krämer, U.; Wimbush, S. C. \& Holzapfel, B. Transmission 373 electron microscopy and high-resolution electron microscopy study of YNi2B2C thin 374 film on Y2O3-Buffered MgO. Chem. Mater. 16, 842-845 (2004).

375 26. Wang, Y. N.; Wei, J.; She, Q.; Pacheco, F. \& Tang, C. Y. Microscopic 376 characterization of FO/PRO membranes-a comparative study of CLSM, TEM and SEM. 377 Environ. Sci. Technol. 46, 9995-10003 (2012).

378 27. Ren, C. L. et al. Synthesis of $\mathrm{Ag} / \mathrm{ZnO}$ nanorods array with enhanced photocatalytic 379 performance. J. Hazard. Mater. 182, 123-129 (2010).

380 28. Lehman, J. H.; Terrones, M.; Mansfield, E.; Hurst, K. E. \& Meunier, V. Evaluating 381 the characteristics of multiwall carbon nanotubes. Carbon. 49, 2581-2602 (2011).

382 29. Haigh, S. J. et al. Cross-sectional imaging of individual layers and buried interfaces 383 of graphene-based heterostructures and superlattices. Nat. Mater. 11, $764-767$ (2012).

384 30. Bravman, J. C. \& Sinclair, R. The preparation of cross-section specimens for 385 transmission electron microscopy. J. Electron. Microsc. 1, 53-61 (1984). 

surface tension on the dislocation structures of diblock copolymers. Macromolecules. 29, 899-906 (1996).

32. Abrahams, M. S. \& Buiocchi, C. Cross-sectional specimens for transmission electron-microscopy. J. Appl. Phys. 45, 3315-3316 (1974).

391 33. Kim, D. H.; Jang, Y.; Park, Y. D. \& Cho, K. Layered molecular ordering of selforganized poly(3-hexylthiophene) thin films on hydrophobized surfaces. Macromolecules. 39, 5843-5847 (2006). 34. Akamatsu, K.; Shimada, M.; Tsuruoka, T.; Nawafune, H.; Fujii, S. \& Nakamura, Y.

395 Synthesis of $\mathrm{pH}$-responsive nanocomposite microgels with size-controlled gold nanoparticles from ion-doped, lightly cross-linked poly(vinylpyridine). Langmuir. 26, 397 1254-1259 (2010).

398 35. Miyachi, M.; Yamanoi, Y.; Tomo, T. \& Nishihara, H. Cross-sectional TEM analysis 399 of an ITO surface coated with photosystem I and molecular wires. J. Inorg. Organomet. $400 \quad P .26,1309-1312(2016)$.

401 36. Moon, J. S.; Lee, J. K.; Cho, S.; Byun, J. \& Heeger, A. J. “Columnlike” structure 402 of the cross-sectional morphology of bulk heterojunction materials. Nano Lett. 9, 230403234 (2009).

404 37. Oleksak, R. P. et al. Chemical and structural investigation of high-resolution 405 patterning with HafSOx. ACS Appl. Mater. Inter. 6, 2917-2921 (2014).

406 38. Yang, K.; Jiang, Y.; Yang, J. J. \& Lin, D. H. Correlations and adsorption 407 mechanisms of aromatic compounds on biochars produced from various biomass at $408700{ }^{\circ}$ C. Environ. Pollut. 233, 64-70 (2018).

409 39. Yang, K.; Zhu, L. H.; Yang, J. J. \& Lin, D. H. Adsorption and correlations of 410 selected aromatic compounds on a $\mathrm{KOH}$-activated carbon with large surface area. Sci. 411 Total. Environ. 618, 1677-1684 (2017).

412 40. Wang, S. S. et al. The sorptive and reductive capacities of biochar supported 413 nanoscaled zero-valent iron (nZVI) in relation to its crystallite size. Chemosphere. 186, $414 \quad 495-500$ (2017). 
41. Cao, Z.; Li, H.; Xu, X. \& Xu, J. Correlating surface chemistry and hydrophobicity

416 of sulfidized nanoscale zerovalent iron with its reactivity and selectivity for denitration

417 and dechlorination. Chem. Eng. J. 394, 124876 (2020).

418 42. Wei, A. L.; Ma, J.; Chen, J. J.; Zhang, Y.; Song, J. X. \& Yu, X. Y. Enhanced nitrate removal and high selectivity towards dinitrogen for groundwater remediation using biochar-supported nano zero-valent iron. Chem. Eng. J. 353, 595-605 (2018).

421 43. Zhu, H. J.; Jia, Y. F.; Wu, X. \& Wang, H. Removal of arsenic from water by 422 supported nano zero-valent iron on activated carbon. J. Hazard. Mater. 172, 1591-1596 423 (2009).

424 44. Lv, X.; Xu, J.; Jiang, G. \& Xu, X. Removal of chromium(VI) from wastewater by 425 nanoscale zero-valent iron particles supported on multiwalled carbon nanotubes.

426 Chemosphere. 85, 1204-1209 (2011).

45. Devi, P. \& Saroha, A. K. Synthesis of the magnetic biochar composites for use as an adsorbent for the removal of pentachlorophenol from the effluent. Bioresource Technol. 169, 525-531 (2014).

430 46. Yang, K.; Wei, W.; Qi, L.; Wu, W. H.; Jing, Q. F. \& Lin, D. H. Are engineered 431 nanomaterials superior adsorbents for removal and pre-concentration of heavy metal 432 cations from water? Rsc Adv. 4, 46122-46125 (2014).

433 47. Brown, H. C. \& Brown, C. A. A simple preparation of highly active platinum metal 434 catalysts for catalytic hydrogenation. J. Am. Chem. Soc. 84, 1494-1495 (1962).

435 48. Zhao, X.; Liu, W.; Cai, Z.; Han, B.; Qian, T. \& Zhao, D. An overview of preparation 436 and applications of stabilized zero-valent iron nanoparticles for soil and groundwater 437 remediation. Water Res. 100, 245-266 (2016).

438 49. Li, J.; Fana, M. J.; Li, M. \& Liu, X. Cr(VI) removal from groundwater using double 439 surfactant-modified nanoscale zero-valent iron (nZVI): Effects of materials in different 440 status. Sci. Total. Environ. 717, 137112 (2020).

441 50. Yang, K.; Yang, J. J.; Jiang, Y.; Wu, W. H. \& Lin, D. H. Correlations and adsorption 442 mechanisms of aromatic compounds on a high heat temperature treated bamboo biochar. 443 Environ. Pollut. 210, 57-64 (2016). 
444 51. Stefaniuk, M.; Oleszczuk, P. \& Ok, Y. S. Review on nano zerovalent iron (nZVI):

445 from synthesis to environmental applications. Chem. Eng. J. 287, 618-632 (2016).

446 52. Hussain, I. et al. Insights into the mechanism of persulfate activation with nZVI/BC 447 nanocomposite for the degradation of nonylphenol. Chem. Eng. J. 311, 163-172 (2017).

448 53. Wu, J.; Zheng, H.; Zhang, F.; Zeng, R. J. \& Xing, B. S. Iron-carbon composite from 449 carbonization of iron-crosslinked sodium alginate for $\mathrm{Cr}(\mathrm{VI})$ removal. Chem. Eng. J. $450 \quad 362,21-29$ (2019).

451 54. Wylie, E. M.; Olive, D. T. \& Powell, B. A. Effects of titanium doping in 452 titanomagnetite on neptunium sorption and speciation. Environ. Sci. Technol. 50, 1853$4531858(2016)$.

\section{Acknowledgements}

456 This work was supported partly by the National Key Research and Development 457 Program of China (2017YFA0207001, 2017YFC0211803), the National Natural 458 Science Foundation of China $(21777138,21621005)$ and the Fundamental Research 459 Funds for the Central Universities (2020FZZX001-06).

\section{Author contributions}

462 Jialu Xu: Writing-original draft. Ming Zhang: Writing-review \& editing. Daohui Lin:

463 Writing-review \& editing. Kun Yang: Supervision, Writing-review \& editing

\section{Competing interests}

465 The authors declare no competing financial interest. 
470 Analysis methods of $\mathrm{Fe}^{2+} / \mathrm{Fe}^{3+}$ in supernatants and solids in the precipitation 471 experiments (Text 1 ), species distribution of $\mathrm{Fe}^{2+} / \mathrm{Fe}^{3+}$ in supernatants and solids in the 472 precipitation experiments (Table S1), schematic of ultra-thin slice of NZVI/BC 473 preparation (Figure S1), SEM image (Figure S2a) and SEM elemental mapping (Figure $474 \mathrm{~S} 2 \mathrm{~b}$ ) of $\mathrm{NZVI} / \mathrm{BC}, \mathrm{N}_{2}$ adsorption-desorption isotherm (Figure S3a), pore size 475 distribution (Figure S3 b) of BC, and C-TEM images of NZVI/BC* (S4 a, c, e) and BC 476 (S4 b, d, f) were presented.

477

478 Corresponding Author

$479 *$ Tel: 86-571-88982589; Fax: 86-571-88982590; E-mail: kyang@ zju.edu.cn 
496 Figure 1. SEM images (a, b) and C-TEM images (c, d) of BC.

497 Figure 2. SEM image (a) and C-TEM image (b) of NZVI.

498 Figure3. SEM images (a, b) and EDX (c) spectrum of NZVI/BC, as well as XRD 499 patterns (d) of $\mathrm{BC}, \mathrm{NZVI} / \mathrm{BC}, \mathrm{NZVI} / \mathrm{BC}^{*}, \mathrm{NZVI}+\mathrm{BC}, \mathrm{NZVI}, \mathrm{NaBH}_{4}$ treated $\mathrm{Fe}(\mathrm{OH})_{2}$ 500 and $\mathrm{NaBH}_{4}$ treated $\mathrm{Fe}(\mathrm{OH})_{3}$.

501 Figure 4. C-TEM images (a, b) of NZVI/BC.

502 Figure 5. SEM (a, b) and C-TEM images (c, d) of NZVI+BC.

503 Figure 6. $\mathrm{pH}$-dependent percent removal curves of $\mathrm{Fe}^{3+}$ or $\mathrm{Fe}^{2+}$ with or without $\mathrm{BC}$.

504 Figure 7. Pictures of suspensions of $\mathrm{Fe}(\mathrm{OH})_{2}$ and $\mathrm{Fe}(\mathrm{OH})_{3}$ precipitates before (a) and 505 after treated with $\mathrm{NaBH}_{4}$ solution (b).

506

507

508

509

510 

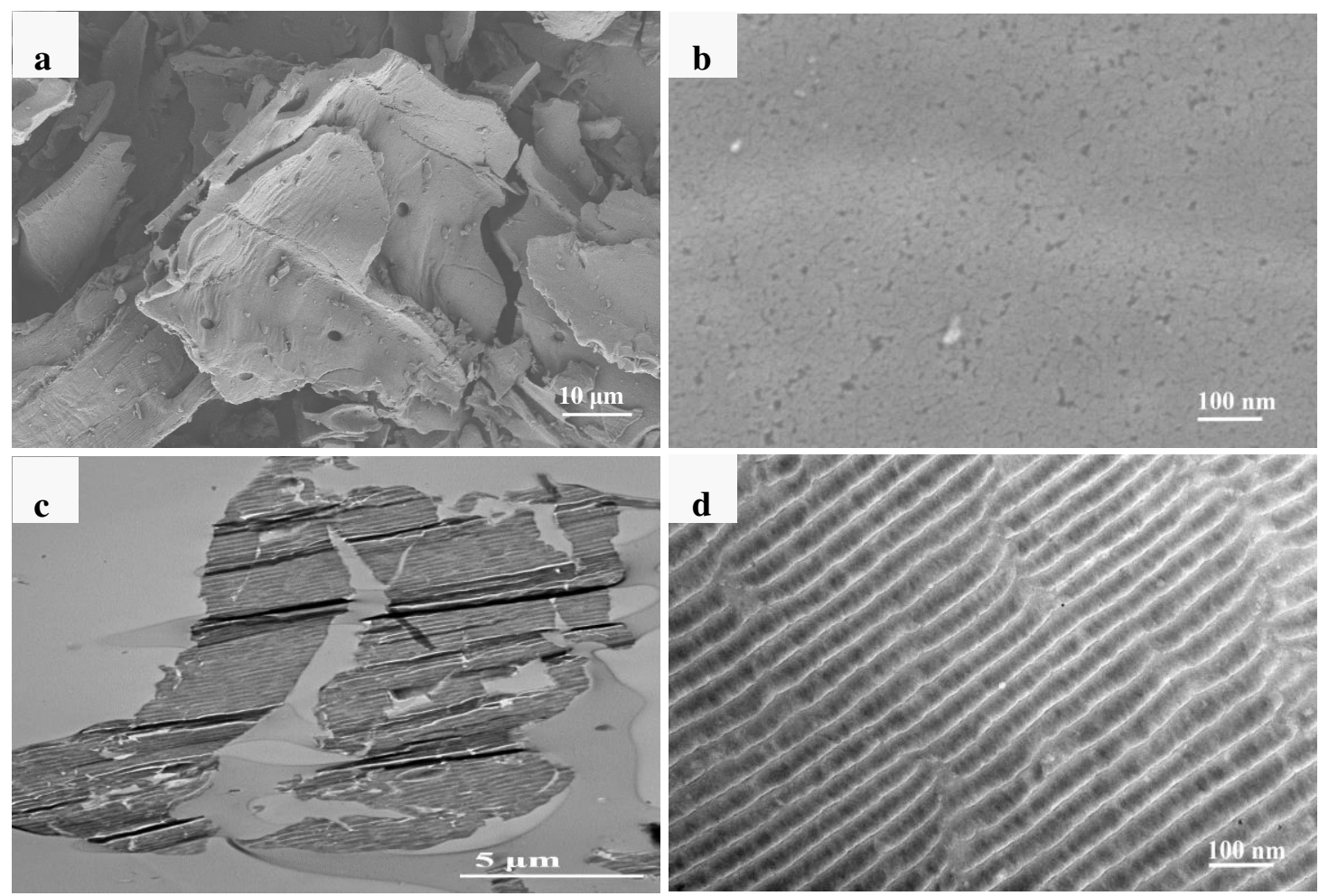

512 Figure 1. SEM images (a, b) and C-TEM images (c, d) of BC.

513

514

515

516

517

518

519

520

521

522

523

524

525

526

527

528

529

530

531

532

533 


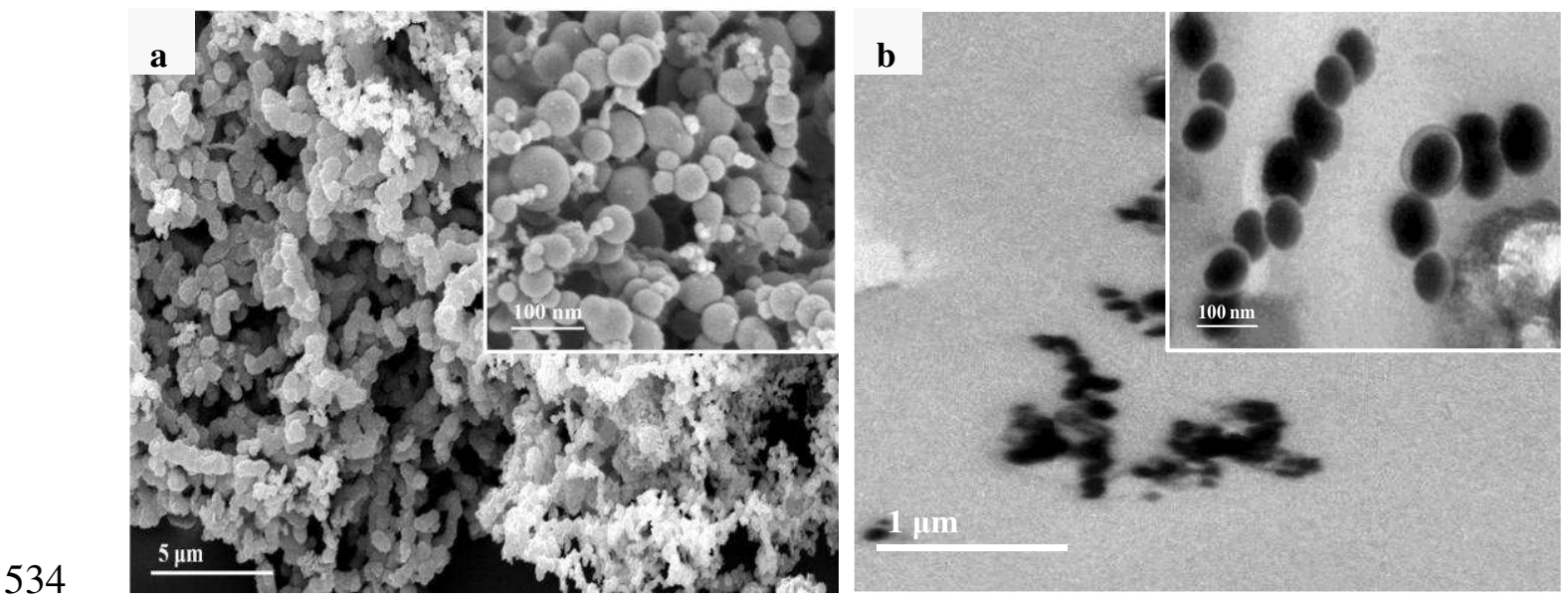

535 Figure 2. SEM image (a) and C-TEM image (b) of NZVI.

536

537

538

539

540

541

542

543 

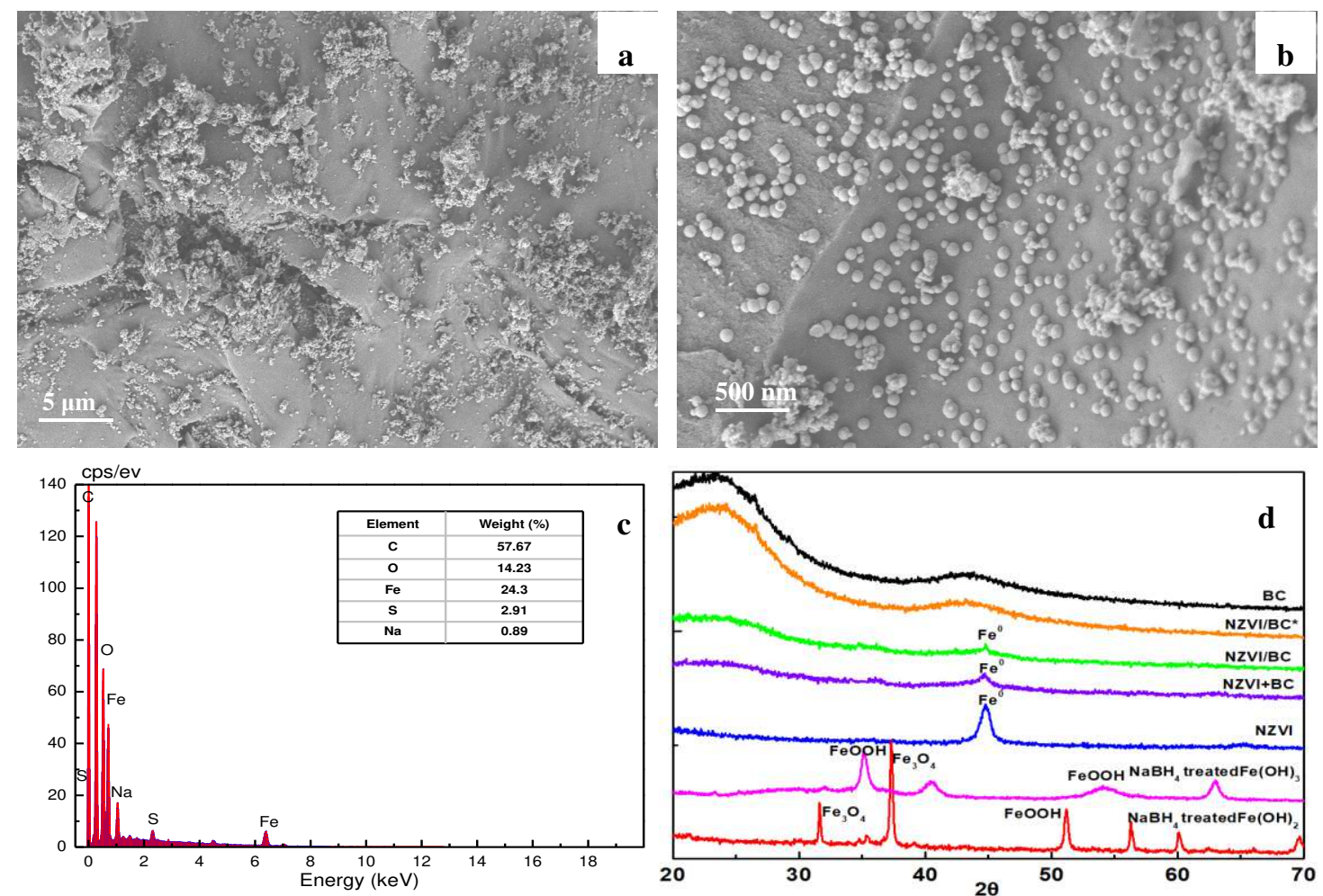

544 Figure3. SEM images $(a, b)$ and EDX (c) spectrum of NZVI/BC, as well as XRD

545 patterns (d) of BC, NZVI/BC, NZVI/BC*, NZVI+BC, NZVI, $\mathrm{NaBH}_{4}$ treated $\mathrm{Fe}(\mathrm{OH})_{2}$ 546 and $\mathrm{NaBH}_{4}$ treated $\mathrm{Fe}(\mathrm{OH})_{3}$. 


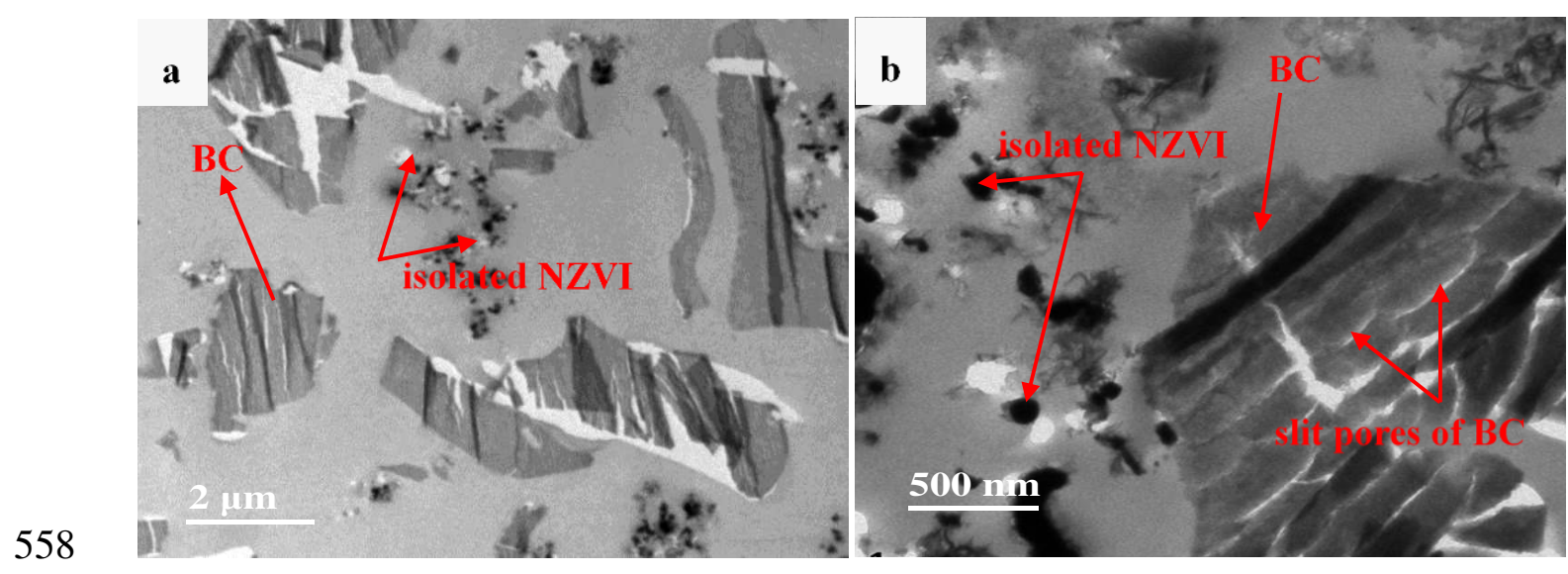

559 Figure 4. C-TEM images $(a, b)$ of NZVI/BC.

560

561

562

563

564

565

566

567

568

569

570

571

572

573

574

575

576

577

578

579

580

581 


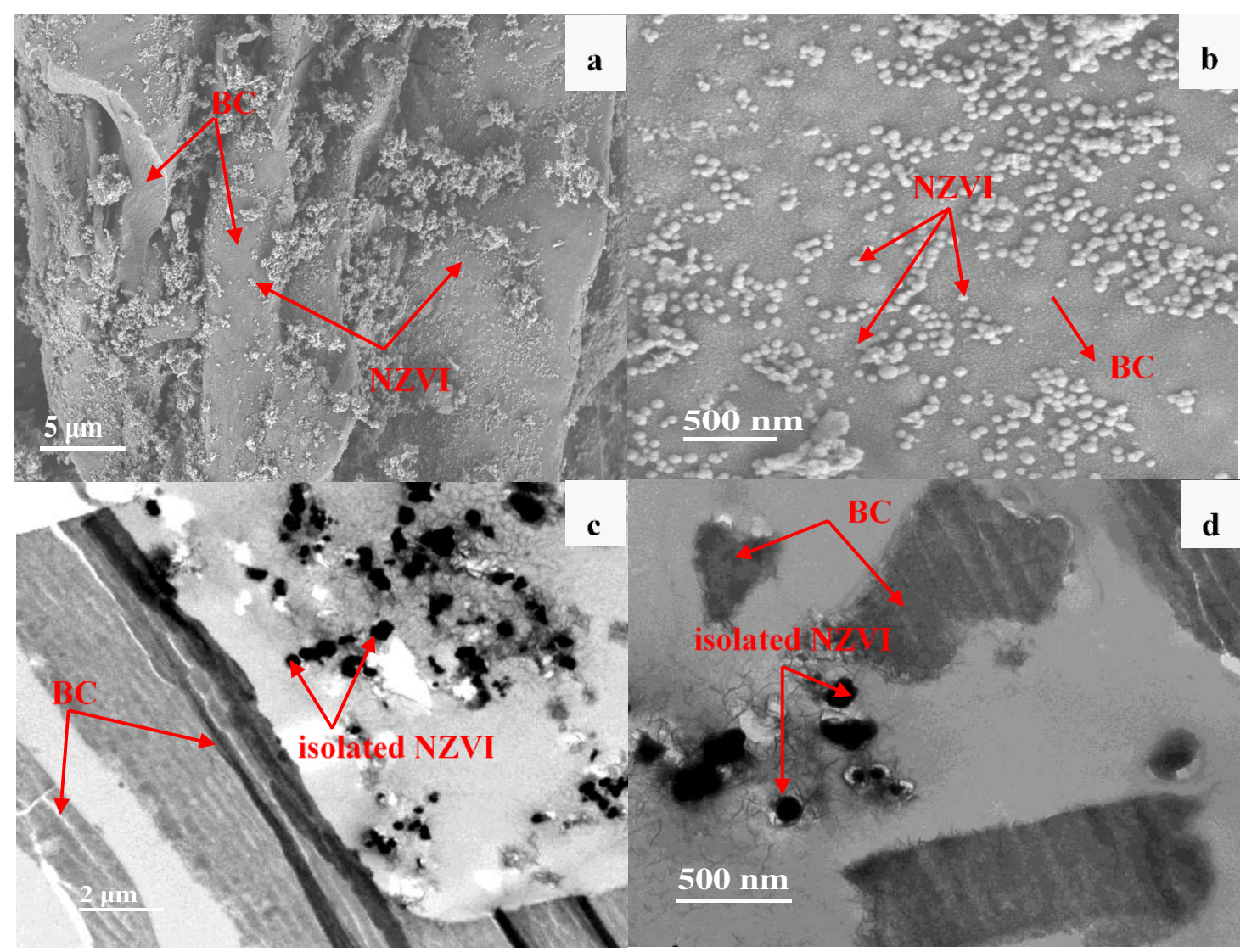

583

Figure 5. SEM $(a, b)$ and C-TEM images $(c, d)$ of NZVI+BC.

584

585

586

587

588

589

590

591

592 

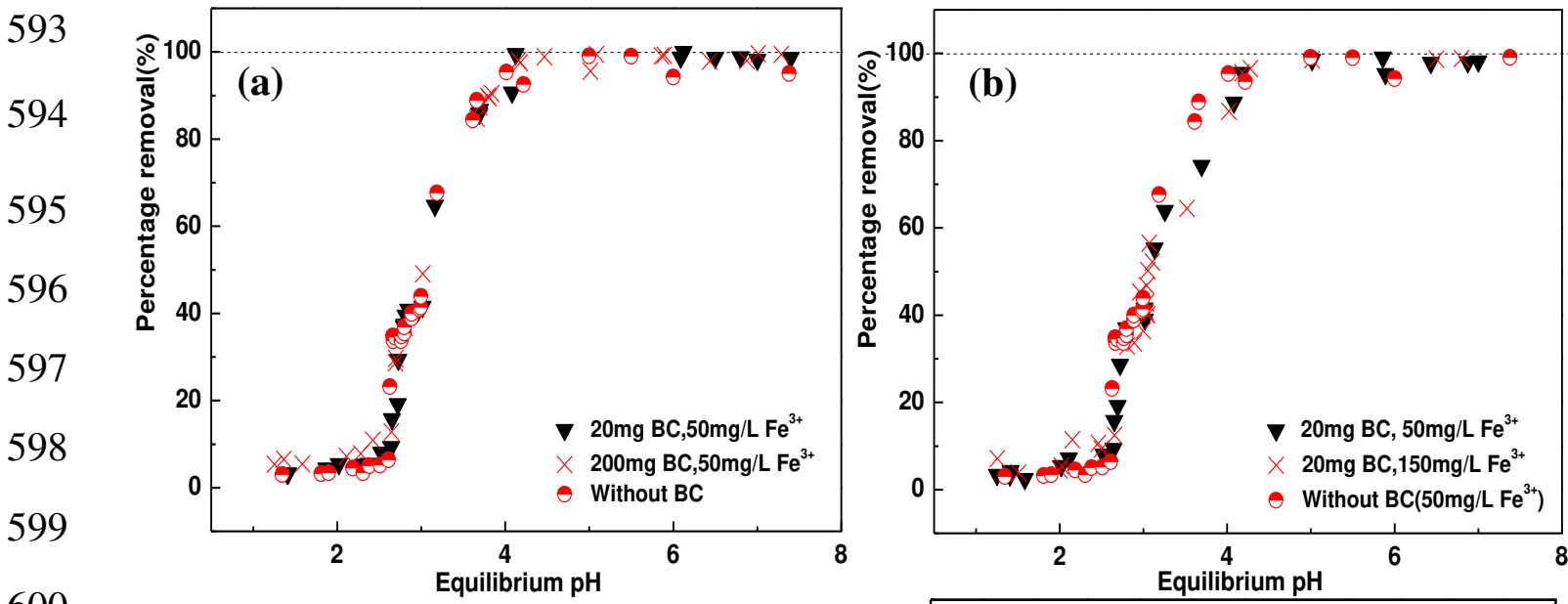

600

601

602

603

604

605

606

607
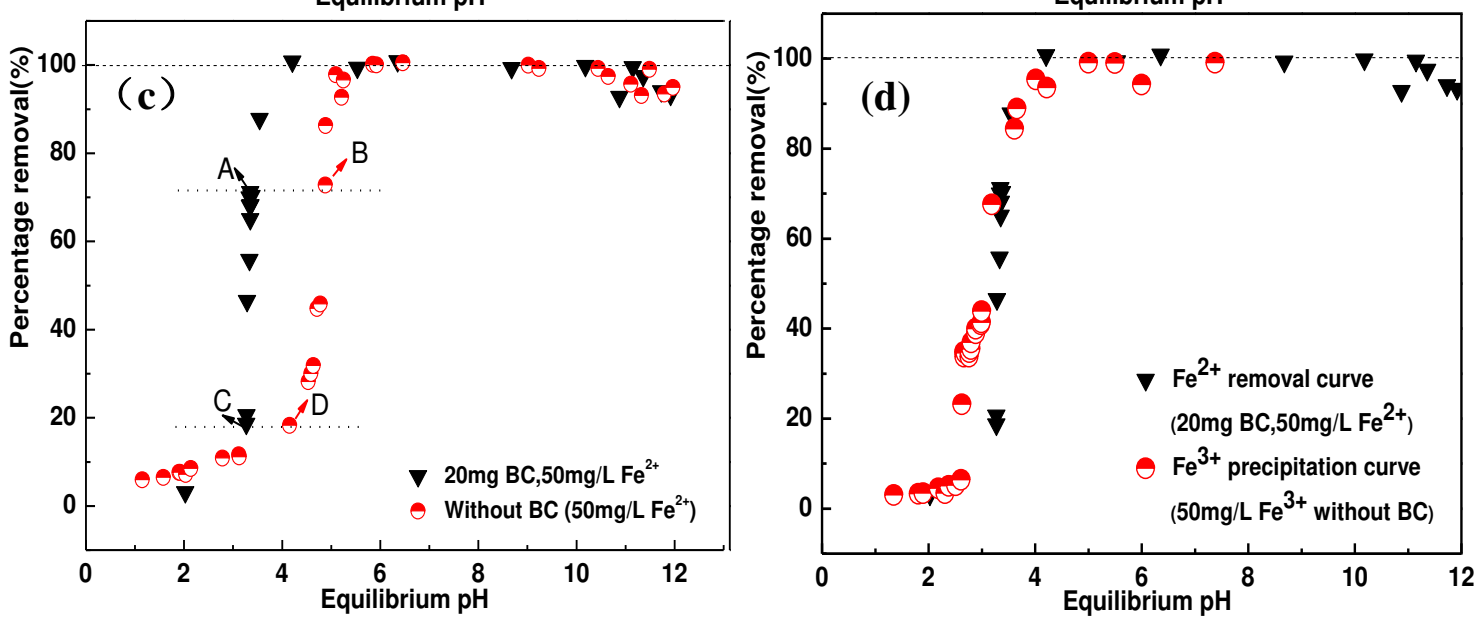

608 Figure 6. $\mathrm{pH}$-dependent percent removal curves of $\mathrm{Fe}^{3+}$ or $\mathrm{Fe}^{2+}$ with or without $\mathrm{BC}$.

609

610

611

612

613

614

615 

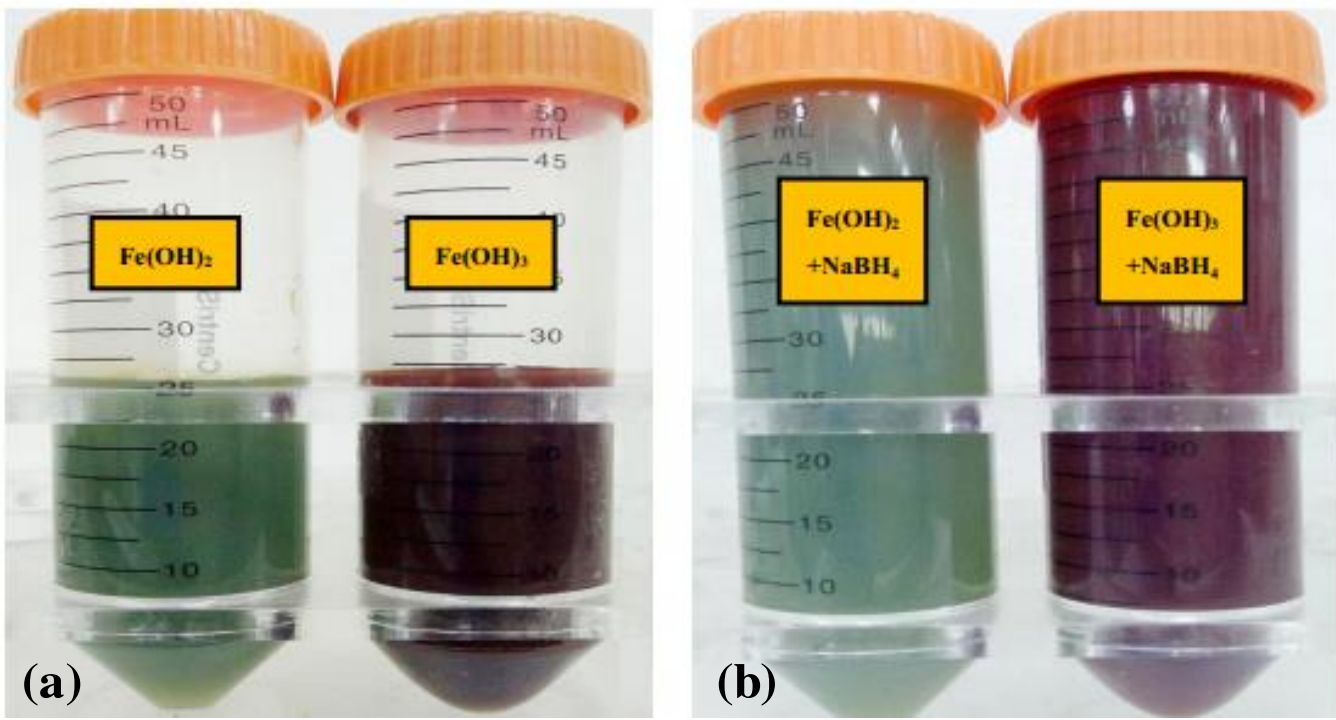

617 Figure 7. Pictures of suspensions of $\mathrm{Fe}(\mathrm{OH})_{2}$ and $\mathrm{Fe}(\mathrm{OH})_{3}$ precipitates before (a) and 618 after treated with $\mathrm{NaBH}_{4}$ solution (b).

619

620

621

622

623

624

625

626

627

628

629 


\section{Figures}
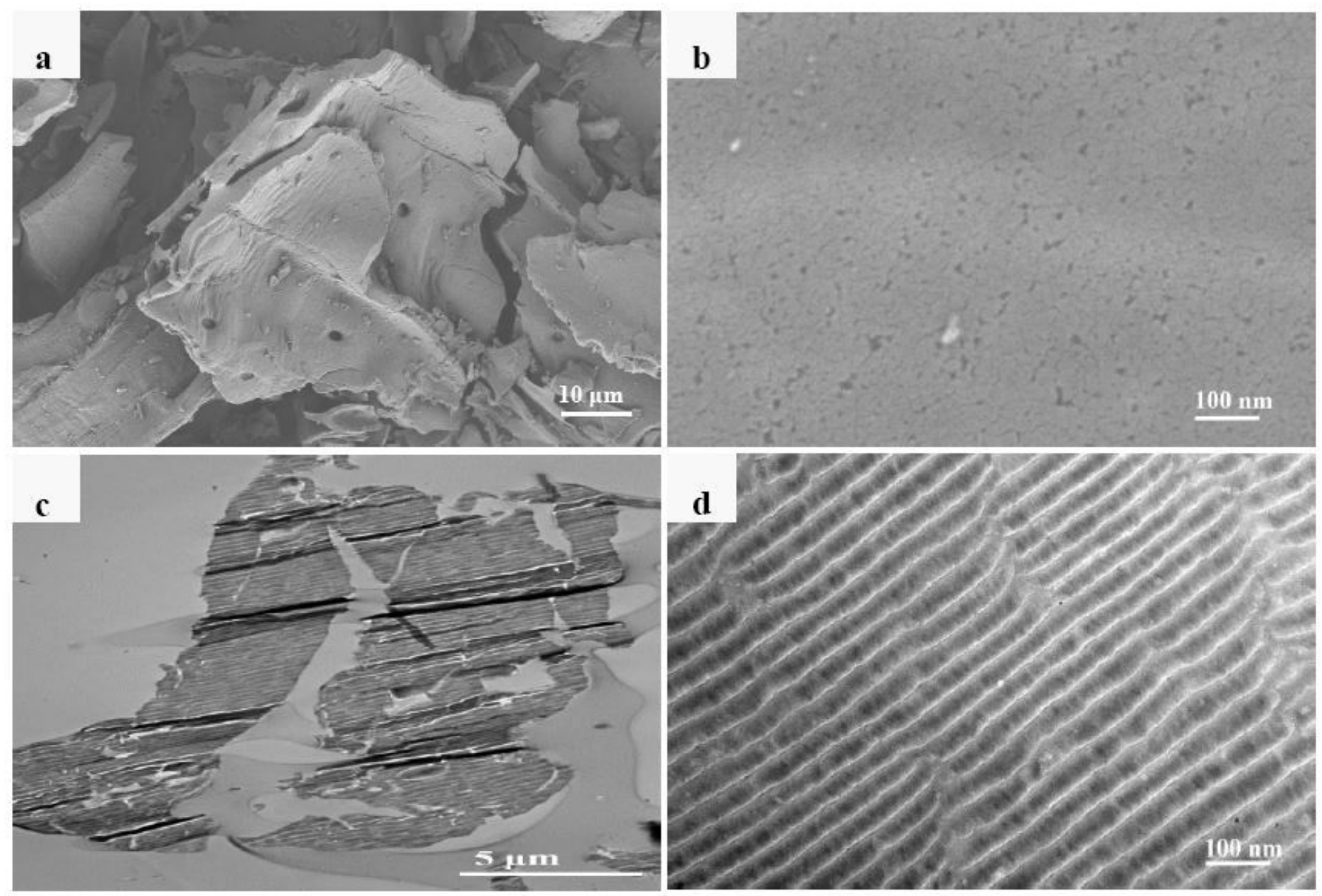

Figure 1

SEM images $(a, b)$ and C-TEM images $(c, d)$ of BC. 

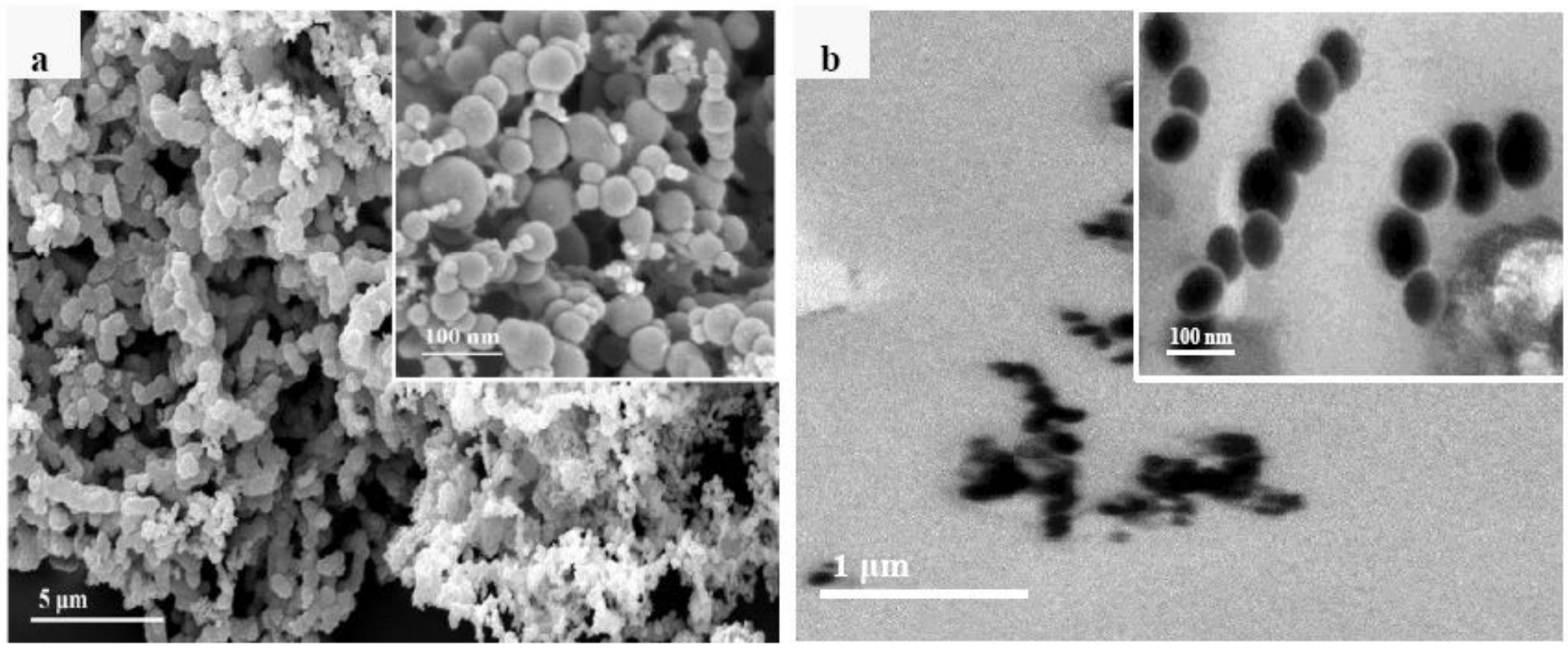

Figure 2

SEM image (a) and C-TEM image (b) of NZVI.
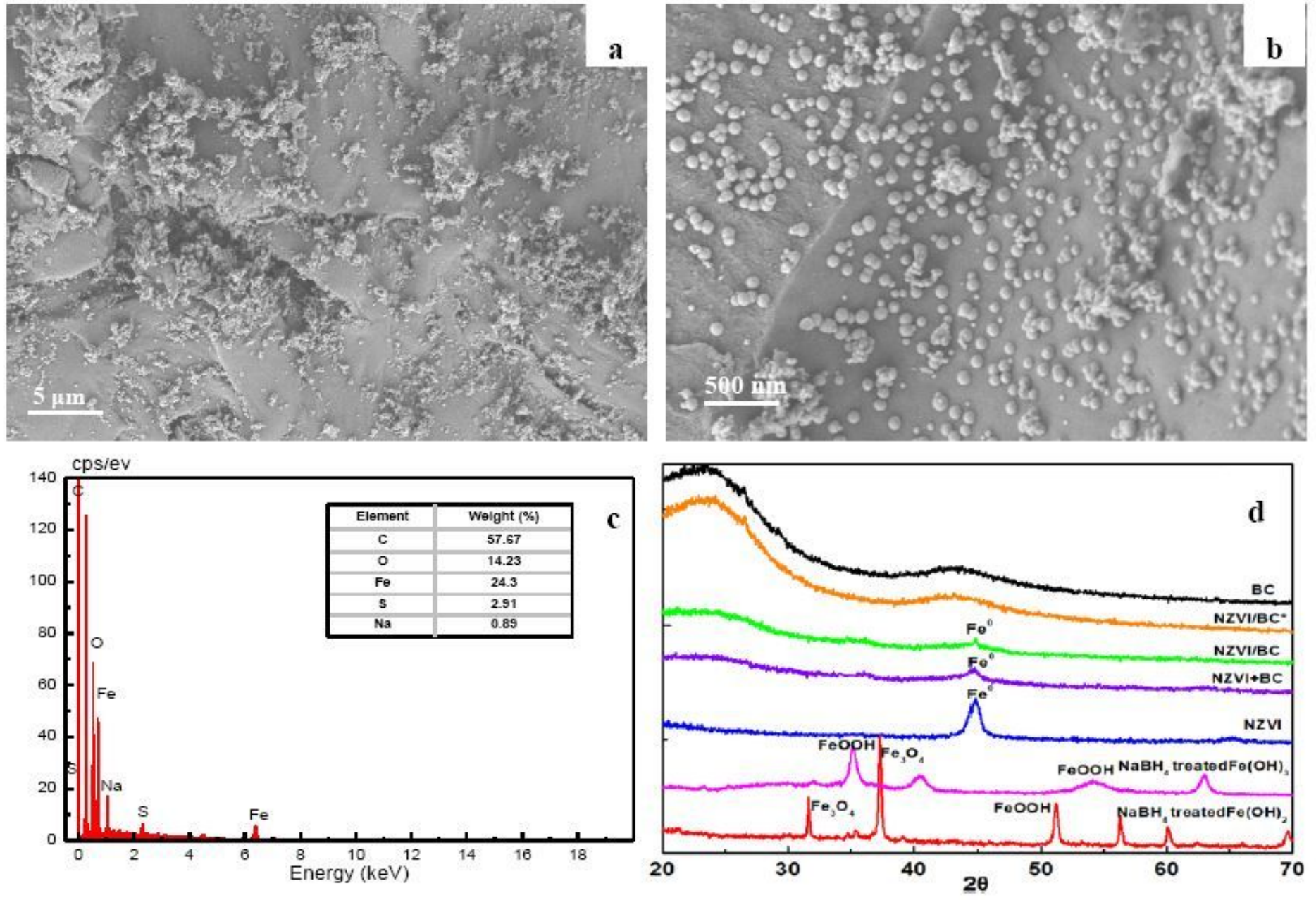

Figure 3 
SEM images (a, b) and EDX (c) spectrum of NZVI/BC, as well as XRD patterns (d) of BC, NZVI/BC, $\mathrm{NZVI/BC*}$, NZVI+BC, NZVI, NaBH4 treated Fe(OH)2 and $\mathrm{NaBH} 4$ treated $\mathrm{Fe}(\mathrm{OH}) 3$.
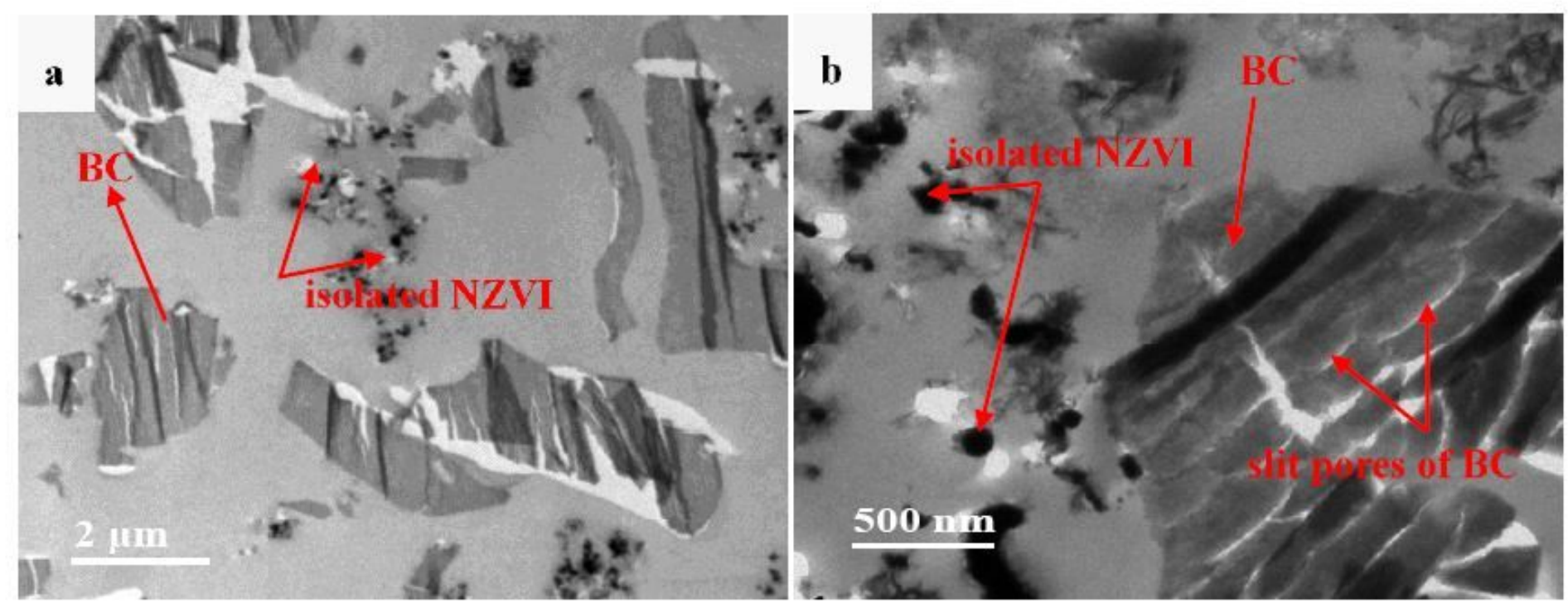

Figure 4

C-TEM images $(a, b)$ of NZVI/BC. 


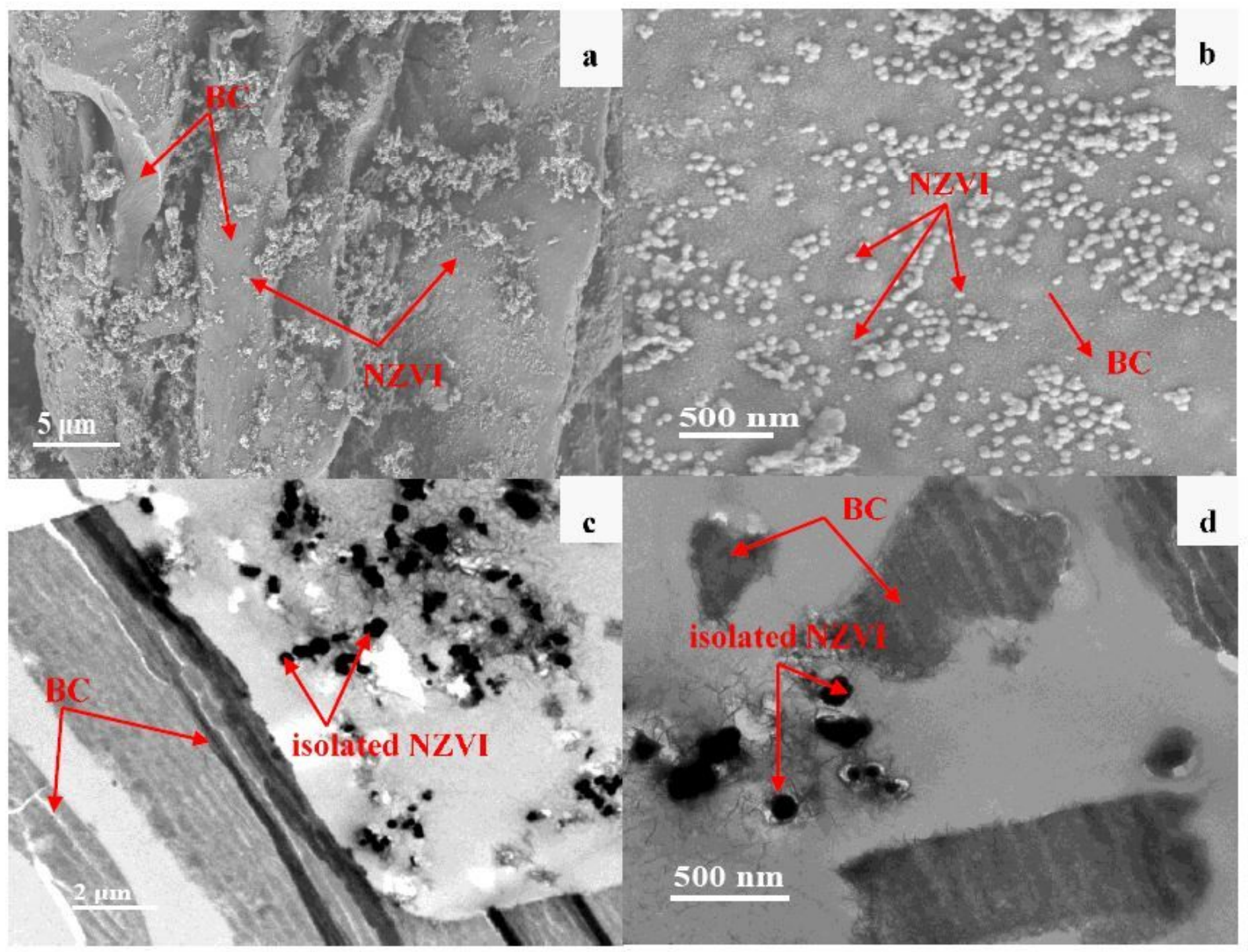

Figure 5

SEM $(a, b)$ and C-TEM images (c, d) of NZVI+BC. 

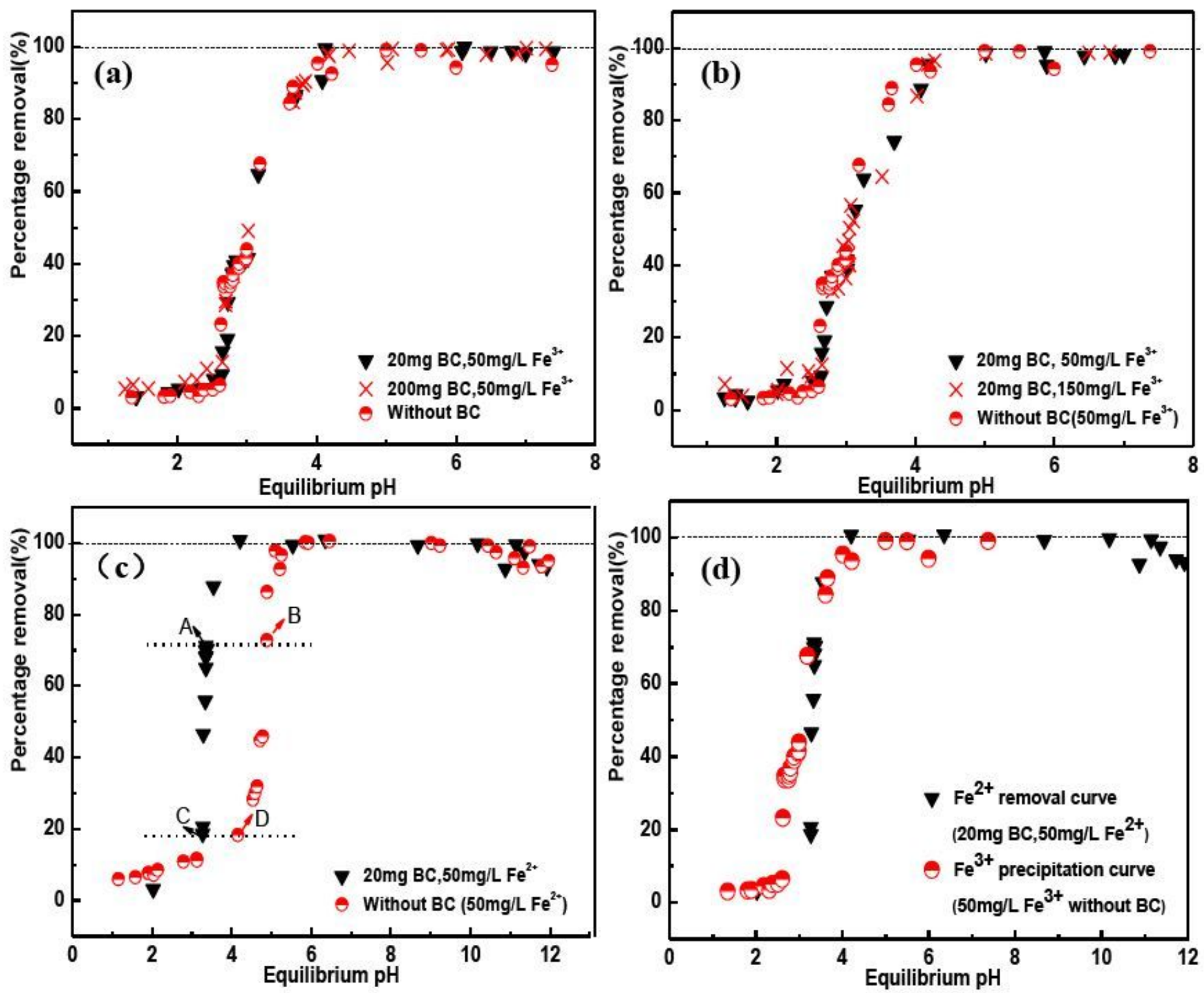

Figure 6

$\mathrm{pH}$-dependent percent removal curves of $\mathrm{Fe} 3+$ or $\mathrm{Fe} 2+$ with or without $\mathrm{BC}$. 

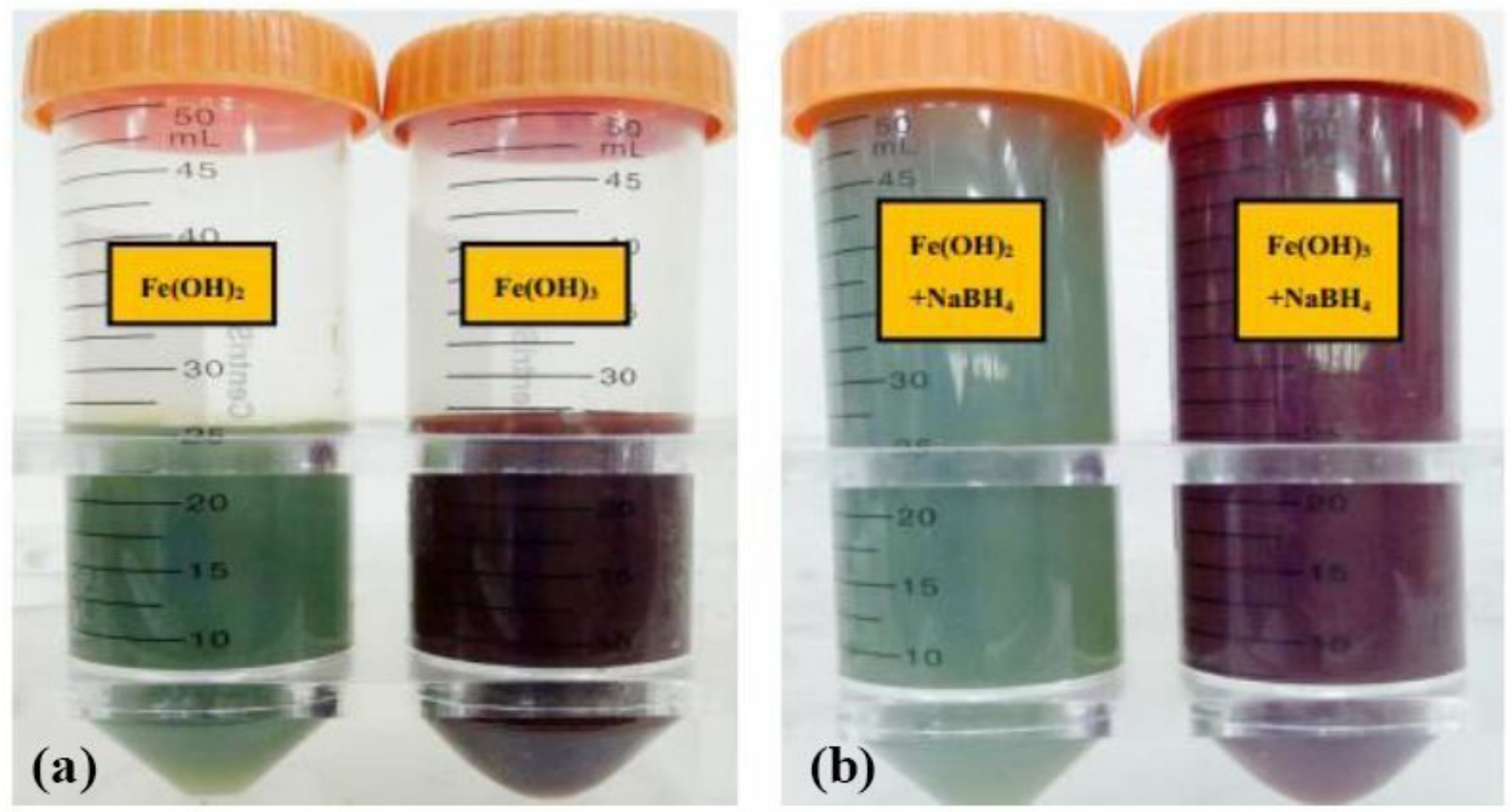

\section{Figure 7}

Pictures of suspensions of $\mathrm{Fe}(\mathrm{OH}) 2$ and $\mathrm{Fe}(\mathrm{OH}) 3$ precipitates before (a) and after treated with $\mathrm{NaBH} 4$ solution (b).

\section{Supplementary Files}

This is a list of supplementary files associated with this preprint. Click to download.

- manuscriptSupportinginformation.pdf

- TOC.jpg 